\title{
Research Paper \\ The Effictiveness of Affective, Behavioral \& Cognitive Leisure Time Cultural Program on the Emotion Regulation of Mothers and Social Skills of Children with Intellectual Disability (ID)
}

\author{
Maral Kamani Mataki ${ }^{1}$, Mohammad Ashori* ${ }^{* 2}$ \\ 1. M.A. Student in General Psychology, Varamin-Pishva Branch, Islamic Azad University, Varamin, Iran
}

2. Assistant Professor, Department of Psychology and Education of People with Special Needs, Faculty of Education and Psychology, University of Isfahan, Iran

Citation: Kamani Mataki M, Ashori M. The effictiveness of affective, behavioral \& cognitive leisure time cultural program on the emotion regulation of mothers and social skills of children with intellectual disability (id). J Child Ment Health. 2021; 7(4): 148-164.

\section{URL: http://childmentalhealth.ir/article-1-716-en.html}

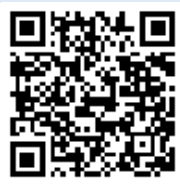

\section{(1)}

do: $10.52547 / \mathrm{jcmh} \cdot 7.4 .10$

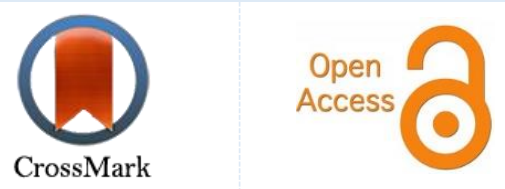

20.1001.1.24233552.1399.7.4.22.0
A R T I C L E I N F O

\section{Keywords:}

Affective,

behavioral \& cognitive leisure time cultural program, emotion regulation, intellectual disability (ID), social skills

Received: 11 Dec 2018 Accepted: 23 Apr 2019 Available: 19 Mar 2021

\section{A B S T R A C T}

Background and Purpose: Affective, behavioral \& cognitive leisure time cultural program is one of the most important programs that can decrease the emotional problems in mothers and enhance the social skills in their children. Therefore, efforts are made here to investigate the effectiveness of this program on the emotion regulation of mothers and social skills of their children with intellectual disability (ID).

Method: This research was a quasi-experimental study with pre-test post-test control group design. The sample consisted of 30 mothers and their children with ID who were selected by convenience sampling and then randomly assigned to either the control or experimental groups. The experimental group underwent 16 sessions of intervention (two 60-min sessions per week), while the control group did not. The instruments of this research were Difficulties in Emotion Regulation Scale (Gratz \& Roemer, 2004) and Evaluation of Social Skills (Matson \& Ollendick, 1983). Independent t-test and MANOVA were used for analyzing the data.

Results: The results showed that Affective, behavioral \& cognitive leisure time cultural program had a significant effect on the emotion regulation of mothers of children with ID $(t=11.22, P=0.0001)$. Furthermore, intervention had a positive and significant effect on the social skills in their children $(\mathrm{t}=10.22, \mathrm{P}=0.0001)$.

Conclusion: Affective, behavioral \& cognitive leisure time cultural program improved the emotion regulation of mothers and increased the social skills in their children with ID. So, planning for use of this cultural program is of particular importance.

* Corresponding author: Mohammad Ashori, Assistant Professor, Department of Psychology and Education of People with Special Needs, Faculty of Education and Psychology, University of Isfahan, Iran.

E-mail: M.ashori@edu.ui.ac.ir

Tel: (+98) 3137935548

2476-5740/ () 2021 The Authors. This is an open access article under the CC BY-NC-ND license

(https://creativecommons.org/licenses/by-nc-nd/4.0/). 


\section{Extended Abstract}

\section{Introduction}

Birth of a child has an important effect on the dynamics of a family $(1,2)$. The presence of a child with intellectual disability can have a considerable effect on the family relationships and cause problems in the family $(2,3)$. A child with ID may threaten mental health and well-being of all family members $(1,7)$. Having a child with ID at home causes different degrees of tension and problems for the family members. However, because of their stronger emotional relationships, mothers are the ones most at risk by problems caused by caring for these children $(3,7)$. Emotion regulation means the ability of a person to face the negative feelings instead of avoiding them at the time of distress and to have a compassionate understanding to achieve important goals $(4,5)$.

Two important components of emotion regulation, including positive reappraisal and positive emotion experience and expression can lead to better interpersonal functioning as well as psychological and individual well-being $(5,22)$. Social skills can be defined as skills that allow a child to interact with others successfully $(6,14)$. Sometimes individuals with a disability have behaviors that are unacceptable in social relationships $(14,23)$. One of the important programs that affect the emotion regulation of mothers of children with ID and increase the social skills of their children is Affective, behavioral \& cognitive leisure time cultural program $(7,15)$. The leisure time is an important issue (13-17) that has a close relationship with emotion regulation and social skills (24-27). Affective, behavioral \& cognitive leisure time cultural program is one of the most important programs that can decrease emotional problems of mothers and enhance social skills of children. Therefore, aim of this study was to investigate the effectiveness of Affective, behavioral \& cognitive leisure time cultural program on the emotion regulation of mothers and social skills of their children with ID.

\section{Method}

The present research was a quasi-experimental study with pre-test post-test control group design. The sample included 30 mothers and their children with ID who were selected by convenience sampling method and then randomly assigned to either the experimental or control groups. The experimental group participated in Affective, behavioral \& cognitive leisure time cultural program for 16 sessions (two 60-min sessions per week), while the control group received no intervention. The instruments of this research were Difficulties in Emotion Regulation Scale (Gratz \& Roemer, 2004) and Evaluation of Social Skills Scale (Matson \& Ollendick, 1983).

To conduct this research, after obtaining the necessary permissions from the Department of Exceptional Education in Tehran, the sample individuals were selected according to the inclusion criteria (age range of 35 to 45 and high school diploma to bachelor's degree for mothers and mild intellectual disability in children) and exclusion criteria (use of psychological services from other centers during the study, the presence of any psychological disorders in mothers, and absence for more than one session in the intervention). First, the objectives of the research were explained to the participants and they completed an informed consent to participate in the research. Difficulties in Emotion Regulation Scale (Gratz \& Roemer, 2004) and Evaluation of Social Skills (Matson \& Ollendick, 1983) were used at the pre-test phase. Then, the Affective, behavioral \& cognitive leisure time cultural program was implemented on the experimental group. After the implementation of the intervention program, both experimental and control groups were post-tested by the same scales. Independent t-test and MANOVA were used to analyze the data.

\section{Results}

Descriptive statistics of emotion regulation, social skills, and their subscales for the experimental and control groups in the pre-test and post-test are showed in Table 1. 
Table 1. Mean and standard deviation of the variables

\begin{tabular}{|c|c|c|c|c|c|}
\hline \multirow{2}{*}{ Variables } & \multirow{2}{*}{ Test } & \multicolumn{2}{|c|}{ Experimental group } & \multicolumn{2}{|c|}{ Control group } \\
\hline & & $\mathrm{M}$ & SD & $\mathrm{M}$ & $\mathrm{SD}$ \\
\hline \multirow{2}{*}{ Rejection of emotional responses } & Pre-test & 21.00 & 1.36 & 21.00 & 1.46 \\
\hline & Post-test & 18.46 & 1.06 & 20.53 & 1.30 \\
\hline \multirow{2}{*}{ Difficulties in purposeful behavior } & Pre-test & 17.06 & 0.96 & 17.40 & 1.05 \\
\hline & Post-test & 15.60 & 0.98 & 17.13 & 1.18 \\
\hline \multirow{2}{*}{ Difficulty in controlling impulse } & Pre-test & 20.33 & 1.23 & 20.20 & 1.08 \\
\hline & Post-test & 18.80 & 0.77 & 20.00 & 1.13 \\
\hline \multirow{2}{*}{ Lack of emotional awareness } & Pre-test & 19.40 & 1.12 & 19.13 & 1.24 \\
\hline & Post-test & 17.46 & 1.06 & 18.86 & 1.18 \\
\hline \multirow{2}{*}{ Limited access to emotional regulation } & Pre-test & 23.33 & 1.39 & 23.20 & 1.32 \\
\hline & Post-test & 21.00 & 1.55 & 23.13 & 1.40 \\
\hline \multirow{2}{*}{ Lack of emotional transparency } & Pre-test & 14.73 & 1.03 & 15.13 & 0.83 \\
\hline & Post-test & 13.00 & 1.41 & 14.86 & 0.99 \\
\hline \multirow{2}{*}{ Total score of emotion regulation } & Pre-test & 115.86 & 3.99 & 116.06 & 3.23 \\
\hline & Post-test & 105.20 & 3.09 & 114.53 & 3.22 \\
\hline \multirow{2}{*}{ Appropriate social skills } & Pre-test & 36.80 & 1.47 & 35.06 & 1.43 \\
\hline & Post-test & 36.80 & 1.47 & 35.26 & 1.53 \\
\hline \multirow{2}{*}{ Antisocial behaviors } & Pre-test & 28.40 & 1.24 & 28.40 & 1.12 \\
\hline & Post-test & 30.66 & 3.37 & 28.60 & 0.98 \\
\hline \multirow{2}{*}{ Aggression and impulsive behaviors } & Pre-test & 28.06 & 1.38 & 28.33 & 1.17 \\
\hline & Post-test & 29.73 & 1.66 & 28.46 & 1.24 \\
\hline \multirow{2}{*}{ Superiority and self-confidence } & Pre-test & 8.20 & 1.08 & 8.40 & 1.24 \\
\hline & Post-test & 9.60 & 1.54 & 8.60 & 1.24 \\
\hline \multirow{2}{*}{ Relationship with peers } & Pre-test & 15.53 & 1.18 & 15.40 & 1.24 \\
\hline & Post-test & 16.80 & 1.52 & 15.66 & 1.34 \\
\hline \multirow{2}{*}{ Total score of social skills } & Pre-test & 115.26 & 3.43 & 115.60 & 2.72 \\
\hline & Post-test & 121.33 & 3.69 & 116.60 & 2.74 \\
\hline
\end{tabular}

At first, the assumptions of normality and homogeneity of variance were confirmed for all variables $(\mathrm{P}>0.05)$ but the assumption of homogeneity of regression slopes was neither confirmed for emotion regulation nor for social skills $(\mathrm{P}<0.05)$. Therefore, two independent t-tests were used for the analysis of gain scores and results indicated that the intervention had a significant effect on the emotion regulation $\left(\mathrm{t}_{(28)}=11.22, \mathrm{P}=0.0001\right)$ and social skills $(\mathrm{t}(28)=10.22, \mathrm{P}=0.0001)$. To determine the effect of the intervention on the subscales of emotion regulation and social skills, the assumptions of homogeneity of variance and homogeneity of variance-covariance matrices were confirmed ( $P>0.05$ ), but the assumption of homogeneity of regression slopes was not confirmed $(\mathrm{P}<0.05)$. Therefore, two MANOVA tests were used for analysis of gain scores of these variables. The results of Wilks's lambda test showed that the subscales of emotion regulation and social skills were significantly different in the experimental and control groups $(\mathrm{P}<0.05)$. Therefore, two MANOVA tests were conducted for gain scores, whose separated results are reported in Tables 5 and 6.

Table 2. MANCOVA results for subscales of emotion regulation

\begin{tabular}{|c|c|c|c|c|c|c|c|}
\hline Dependent variables & Sum of quares & df & Mean square & F statistic & Sig. & Eta squared & Test power \\
\hline Rejection of emotional responses & 30.00 & 1 & 30.00 & 48.09 & 0.0001 & 0.48 & 1.00 \\
\hline Difficulties in purposeful behavior & 10.80 & 1 & 10.80 & 20.61 & 0.0001 & 0.42 & 0.99 \\
\hline Difficulty in controlling impulse & 14.70 & 1 & 14.70 & 20.58 & 0.0001 & 0.52 & 0.99 \\
\hline Lack of emotional awareness & 24.30 & 1 & 24.30 & 31.11 & 0.0001 & 0.52 & 1.00 \\
\hline Limited access to emotional regulation & 38.53 & 1 & 38.53 & 66.32 & 0.0001 & 0.70 & 1.00 \\
\hline Lack of emotional transparency & 16.13 & 1 & 16.13 & 20.65 & 0.0001 & 0.42 & 0.99 \\
\hline
\end{tabular}


Table 3. MANCOVA results for subscales of social skills

\begin{tabular}{cccccccc}
\hline Dependent variables & Sum of quares & df & Mean square & F statistic & Sig. & Eta squared & Test power \\
\hline Appropriate social skills & 17.63 & 1 & 17.63 & 67.32 & 0.0001 & 0.70 & 1.00 \\
Antisocial behaviors & 4.03 & 1 & 4.03 & 21.17 & 0.0001 & 0.43 & 0.99 \\
Aggression and impulsive behaviors & 17.63 & 1 & 17.63 & 97.44 & 0.0001 & 0.71 & 1.00 \\
Superiority and self-confidence & 10.80 & 1 & 10.80 & 37.80 & 0.0001 & 0.57 & 1.00 \\
Relationship with peers & 7.50 & 1 & 7.50 & 35.79 & 0.0001 & 0.56 & 1.00 \\
\hline
\end{tabular}

According to Tables 2 and 3, the intervention had a significant effect on the rejection of emotional responses, difficulties in engaging in purposeful behavior, difficulty in controlling impulse, lack of emotional awareness, limited access to emotional regulation strategies, and lack of emotional transparency $(\mathrm{P}=0.0001)$. Also, the intervention had a significant effect on appropriate social skills, antisocial behaviors, aggression and impulsive behaviors, superiority and self-confidence, and relationship with peers $(\mathrm{P}=0.0001)$.

\section{Conclusion}

Affective, behavioral \& cognitive leisure time cultural program improved emotion regulation in mothers and increased the social skills in their children with ID. Results were consistent with the findings of Kam et al., Zare and Maleki, Hoshina et al., and Lee et al (16-19). To explain this finding, it can be said that applying leisure time program was associated with positive and effective outcomes (14, 15). Through Affective, behavioral \& cognitive leisure time cultural program Affective, behavioral \& cognitive leisure time cultural program, mothers and their children with ID will be well acquainted with the role and importance of leisure time $(7,15)$. As higher level of emotion regulation in mothers and social skills in children leads to effective communication between parents and their children, Affective, behavioral \& cognitive leisure time cultural program can improve the emotion regulation in mothers and increase the social skills in their children with ID. Therefore, paying attention to this program is essential, and planning for its training is of particular importance.
The important strength of the present research was the simultaneous focus on mothers and their children with ID. In summary, use of Affective, behavioral \& cognitive leisure time cultural program was associated with effective results. Since the quasiexperimental method was used in the present study, generalization of the results must be made cautiously. Another limitation of this study was the use of Affective, behavioral \& cognitive leisure time cultural program for mothers of children with ID. It is recommended that this program be used for parents of children with ID. Also, the program can be used for other groups of students with special needs.

\section{Ethical Considerations}

Compliance with ethical guidelines: The permission for conducting this research on sample people was issued by the Department of Exceptional Education in Tehran on 06 Oct.2018. Also, other ethical considerations like gaining the informed consent of the participants and the confidentiality were observed in this research.

Funding: This study was conducted as a Master's thesis with no financial support.

Authors' contribution: This research is taken from master's thesis of Ms. Maral Kamani Matki in the field of general psychology in Varamin-Pishva Branch of Azad University with the code 14320706971001, dated 03 Sep. 2018. The first author was the senior researcher and the second author was the supervisor.

Conflict of interest: There is no conflict of interest in this study and the results have been reported quite clearly.

Acknowledgments: We would like to thank all the authorities of the Department of Exceptional Education in Tehran, especially the research expert, who made the required collaborations for the implementation of training and research, as well as the administrative staff, teachers and sample people who helped us in the implementation of this project. 


\section{اثربخشى برنامه فرهنگى اوقات فر اغت عاطفى، رفتارى، و شناختى (عرش) بر تنظيم هيجان مادران و مهارتهاى اجتماعى كود كان كم توان ذهنى \\ مارال كمانى ماتكى '، محمد عاشورى

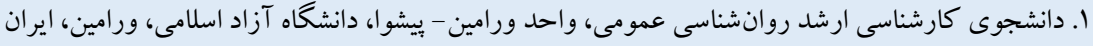

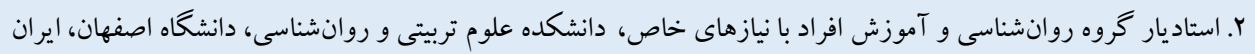

\begin{tabular}{|c|c|}
\hline جكيده & 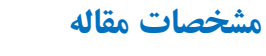 \\
\hline زمينه و هدف: برنامه فرهنگى اوقات فراغت عرش يكى از مهم ترين برنامههايى است كه مىتواند موجب كاهش مشكلات هيجانى مادران & كليدوازهها: \\
\hline و افزايش مهارتهاى اجتماعى فرزندان آنها شود. بنابراين، يُروهش حاضر با هدف بررسى اثربخشى اين برنامه بر تنظيم هيجان مادران و & 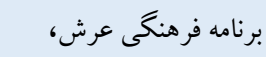 \\
\hline مهارت هاى اجتماعى كود كان كمتوان ذهنى انجام شد. & 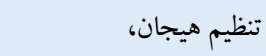 \\
\hline 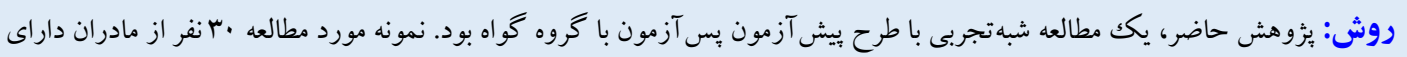 & 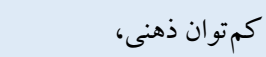 \\
\hline كود كان كمتوان ذهنى و فرزندان آنها بودند كه به شيوه نمونه گيرى در دسترس انتخاب و به صورت تصادفى در دو گروه آزمايش و گو اه & مهارتهاى اجتماعى \\
\hline جايدهى شدند. افراد گروه آزمايش در 19 جلسه در برنامه مداخلهاى (هفتهاى Y جلسه •ودقيقه) شركت كردند؛ در حالى كه به كروه گواه، & \\
\hline 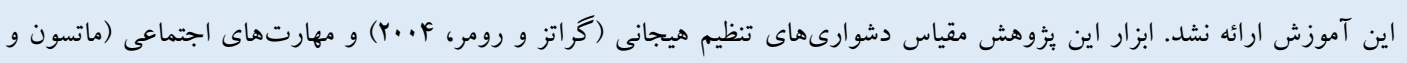 & \\
\hline 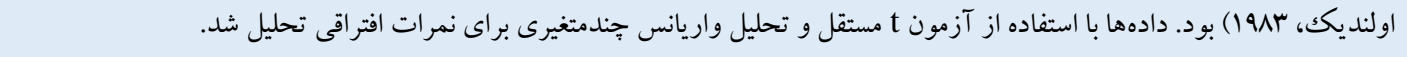 & \\
\hline 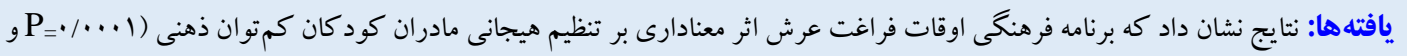 & \\
\hline 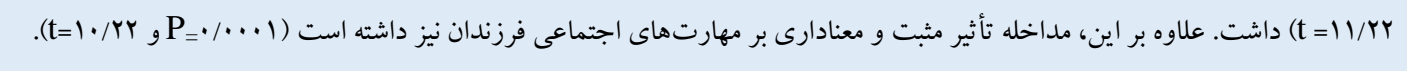 & \\
\hline نتيجه كيرى: برنامه فرهنگى اوقات فراغت عرش سبب بهبود تنظيم هيجانى در مادران و مهارتهاى اجتماعى در فرزندان كمتوان ذهنى & 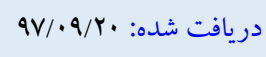 \\
\hline آنها شد؛ بنابراين، برنامهريزى به منظور استفاده از اين برنامه اهميت ويزٔهاى دارد. استلزامات نتايج به دست آمده در مقاله مورد بحث قرار & 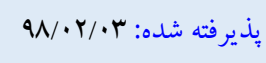 \\
\hline 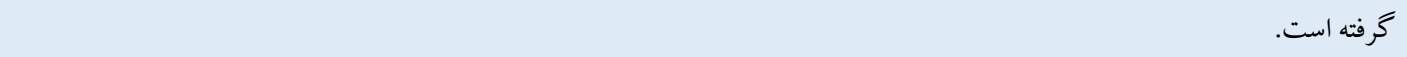 & 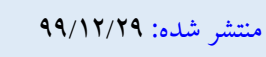 \\
\hline
\end{tabular}

* نويسنده مسئول: محمد عاشورى، استاديار كروه روانشناسى و آموزش افراد با نيازهاى خاص، دانشكده علوم تربيتى و روانشناسى، دانشخاه اصفهان، ايران.

M.ashori@edu.ui.ac.ir رايانامه 
براى برقرارى روابط مثبت با ديخران، ايجاد و گسـترش اعتماد و روابط

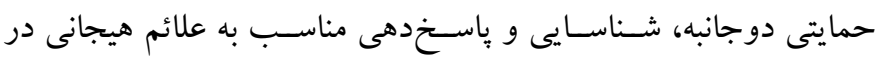

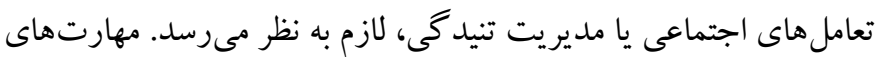

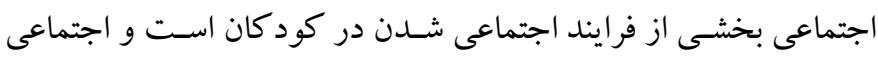

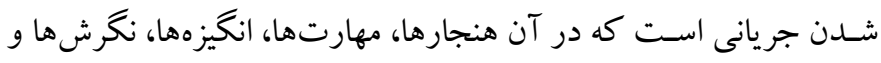

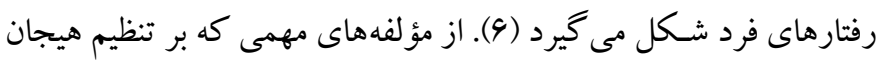

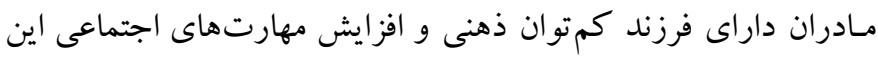

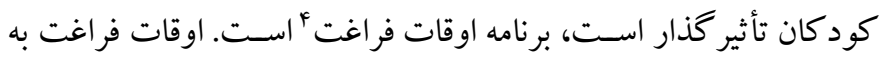

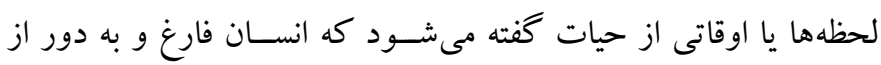
وظايف موظف، آزاد از برداختن به نيازهاى زيستى و فارغ از فريضه هاى

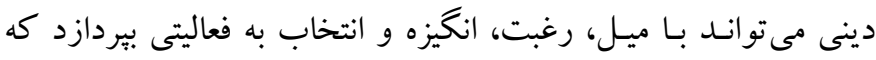

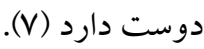

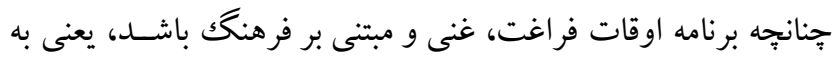

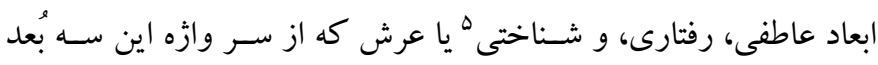

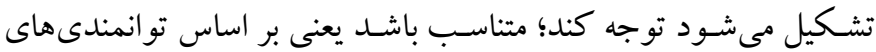

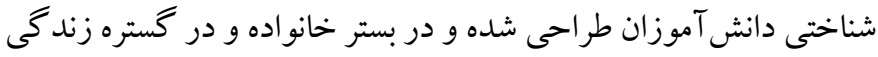

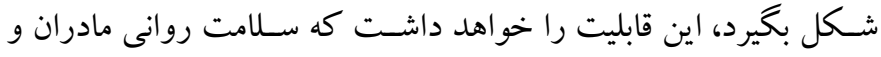

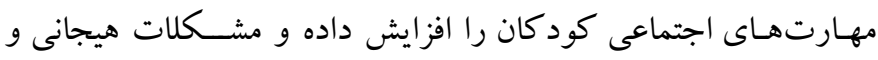

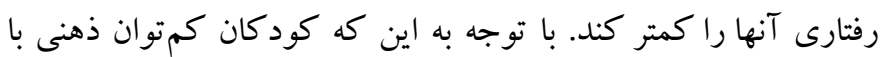
مشـكلات زيادى مواجه هسـتند، اوقات فراغت آنها بيشـتر جنبه آسـيب

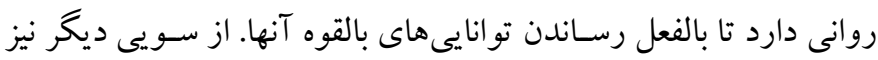

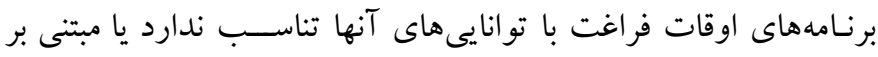

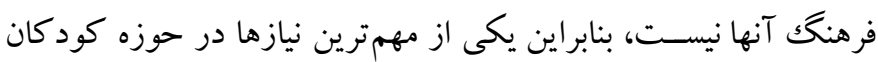

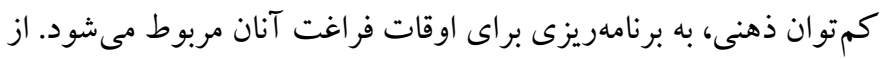

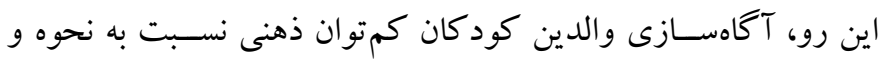

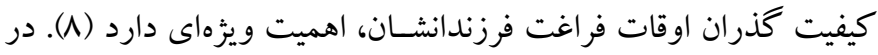
راستاى بومى سازى و فرهنگى كردن برنامه اوقات فراغت، ضرورى است

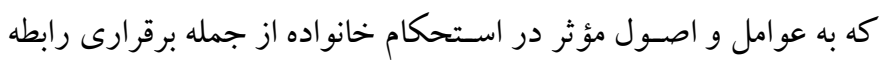

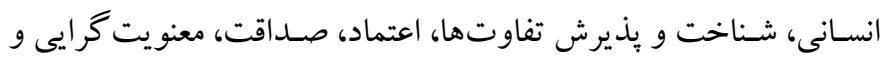

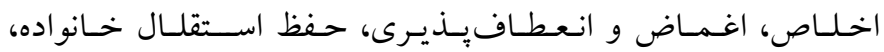

4. Leisure time

5. Affective, behavioral \& cognitive مقلdo تولـد هر كودكك تأثير مهمى بر يويايى هاى خانو اده دارد (او Y). تولد و حضــور كودكى كمتوان ذهنى' مى تواند آثار قابل توجهى بر خانواده، اعضاى آن و روابط خانو اددى بر جاى گذارد، به عملكرد خانو اده آسيب رساند و در نهايت منجر به بروز مشكلاتى در خانواده شود (Y). كودكك كمتوان ذهنى ممكن اسـت ســلامت روان و بهزيسـتى خانو اده را تهلديد

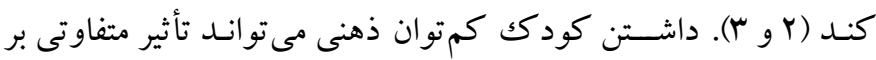
اعضاى خانو اده بكذارد و مشكلات مختلفى را براى هر يكك از آنها ايجاد

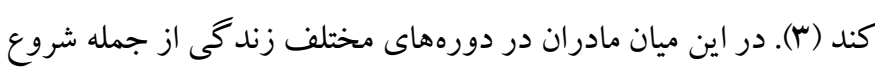

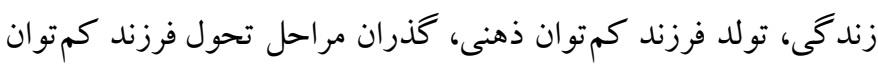

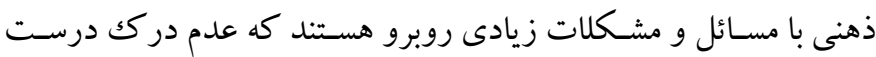

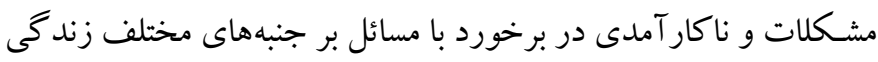
آنها تأثير مى گذارد و در صـورت ارزيابى سـطحى و نامناسـب، ممكن

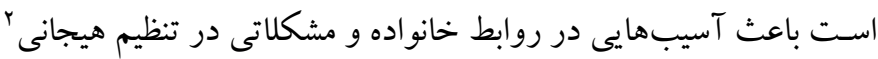

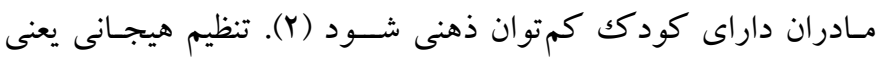
توانيى فرد در روبرو شدن با هيجان منفى (وقتى نمى توان هيجان منفى را

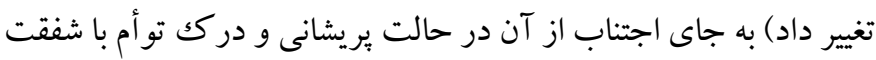

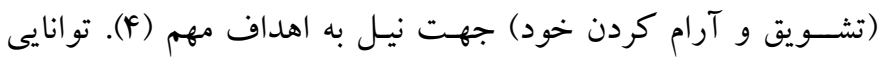

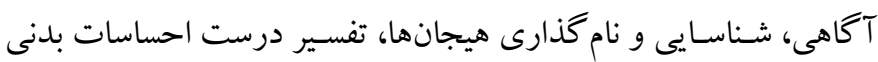

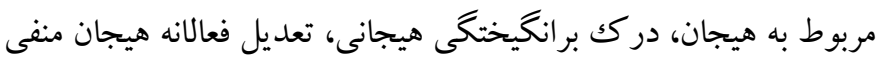
در رسيدن به احسـاس بهتر، و يذيرش هيجان منفى در زمان لزوم تحمل

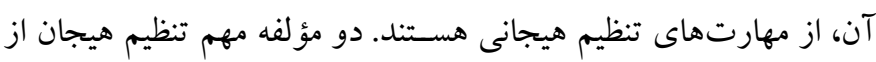

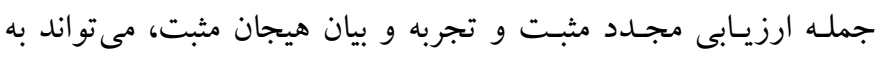

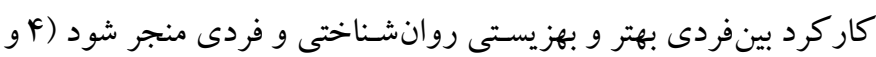

علاوه بر اين شـرايط در حال كذر جامعه، زندكى اجتماعى كود كان

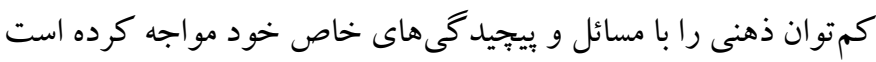

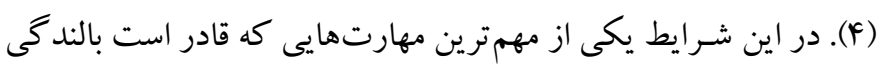

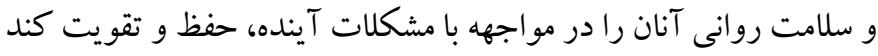

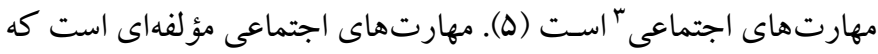

1. Intellectual disability

2. Emotional regulation

3. Social skills 
خانو ادههاى كود كان كمتوان ذهنى است (ها و 19) و اجراى يكك برنامه اوقات فراغت غنى و مبتنى بر فرهنگك به مهار رفتارى و بهبود كيفيت

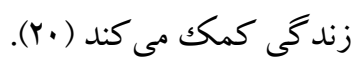

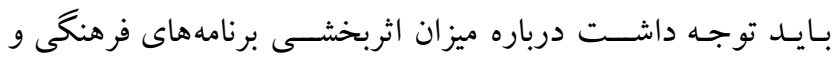

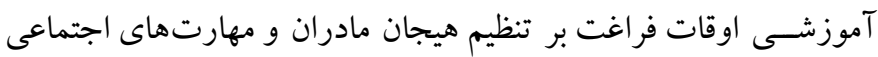

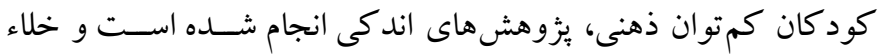

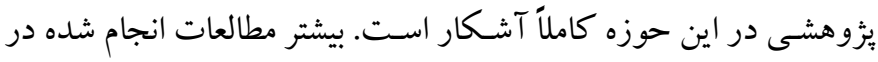

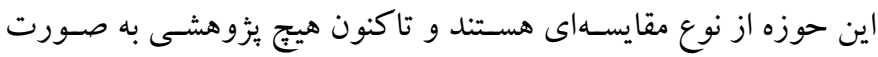

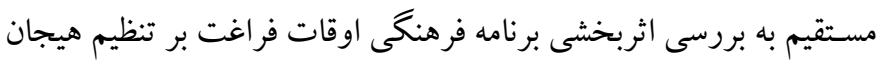
مـادران كودكـان كمتوان ذهنى و مهارتهـاى اجتماعى فرزندان آنها

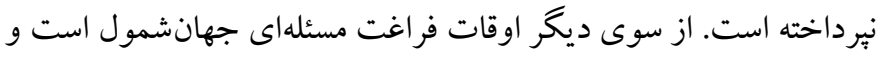
بايد از منظر دينى، فلسفى، اجتماعى، روانشناختى و تربيتى به آن يرداخته

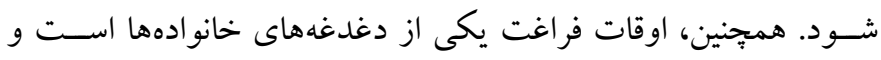

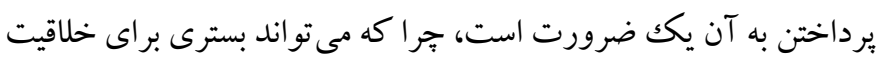

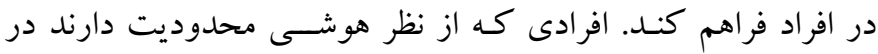

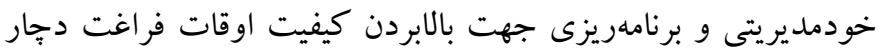

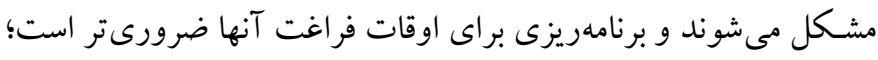

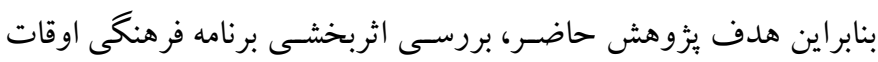

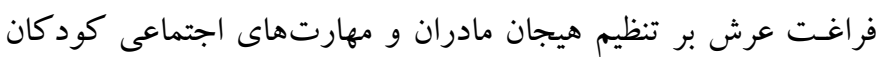

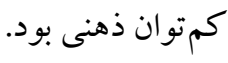

روش

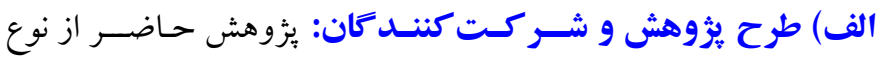

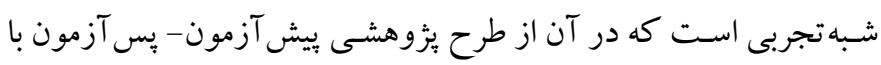

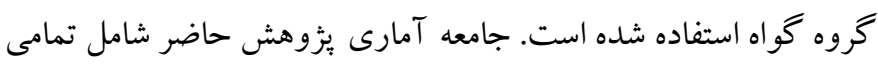

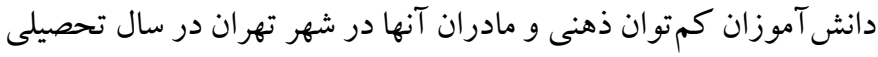
r

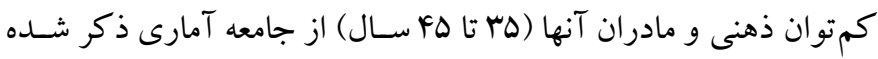

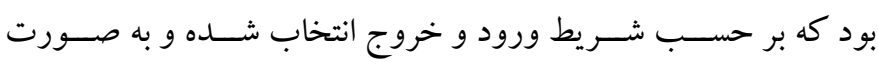

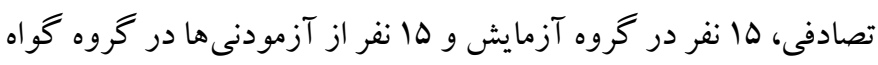

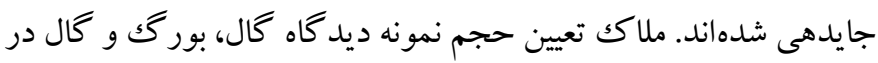

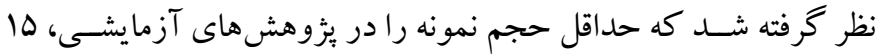

مسئوليتيذيرى و مهار احسـاسات، برخورد مثبت و انتقاديذيرى، تعديل

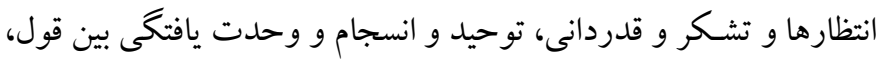

عو اطف، هيجان، و شناخت، توجه ويزهاى مى شود (9).

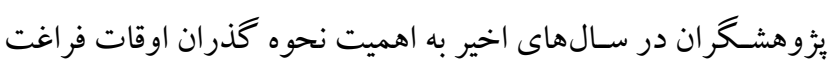
و ارتبـاط احتمالى ميان كيفيت برنامه اوقات فراغت و حوزههاى مختلف مـانتـد افزايش توانممنـدى هـاى اجتماعى و رفع مشـــكلات رفتارى توجه

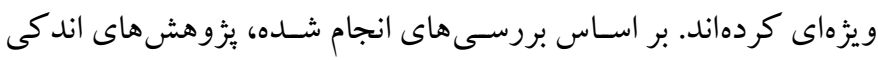
درباره اثربخشـى برنامه اوقات فراغت انجام شـده اسـت. براى مثال، نتايج

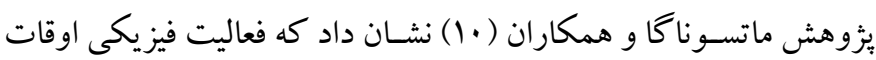
فراغت بيشـترين نقش رادر كاهش خطر ابتلا به كمتوانى جسـمى دارد. نتايج يزٔوهش بوسينك ون در بوتن و ولاسكامٍ (11) بيانگر سطح بايين

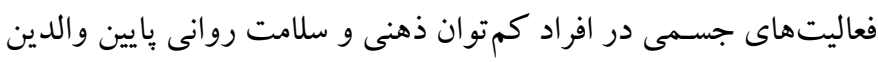

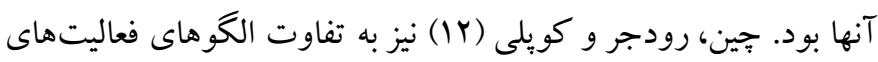

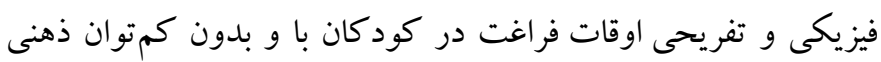

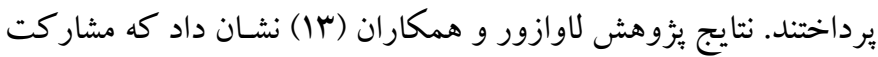
اجتماعى و فراوانى فعاليتهاى تفريحى بعد از بهرهمندى از برنامه اوقات فراغت در گروه نمونسه افزايش يـافت. يافتهاى يزٔوهش ايراتى (IF) حاكى از اثربخشـى برنامههاى اوقات فراغت بر مهارتهاى اجتماعى و

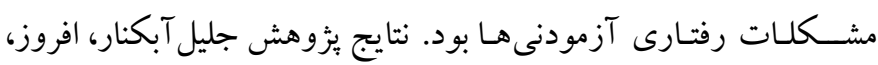
ارجمندنيا و غبارىبناب (10) حاكى از اثربخشسى مثبت و معنادار برنامه

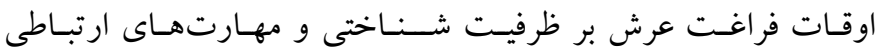

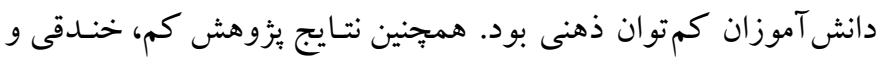

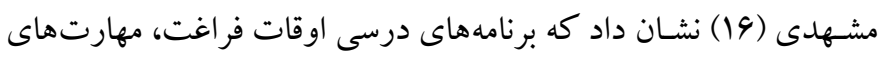
فراغتى و ســامت روانى دانش آموزان را بهطور معنادارى افزايش داده اسـت. در همين راستا يافتهاى بروهش زارع و مالكى عذارى (IV) نشان

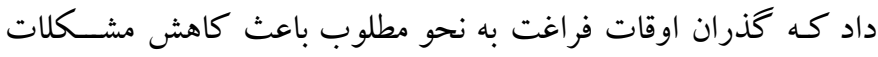
رفتارى دانش آموزان شد. نتايج يزوهش هوشينا، جيانويلو و سو كايا (1)

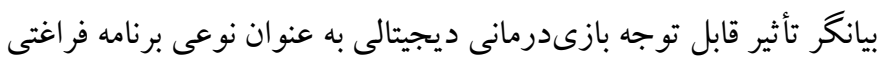

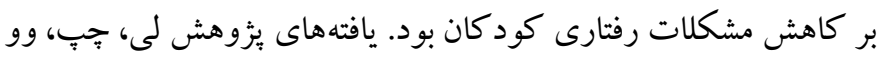

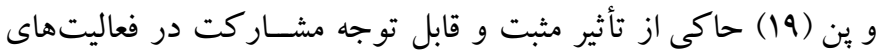

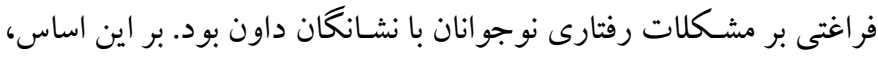

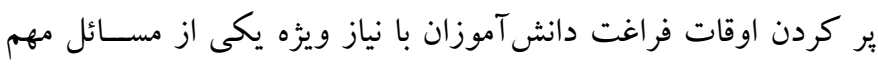




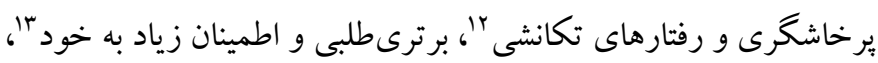

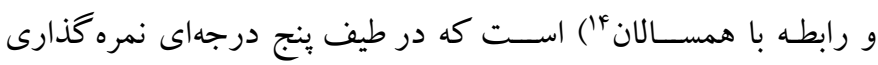

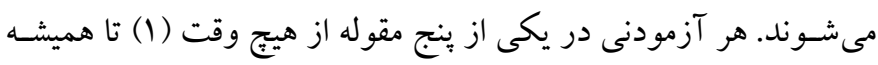

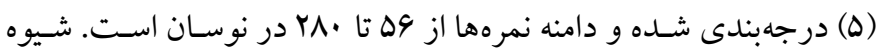

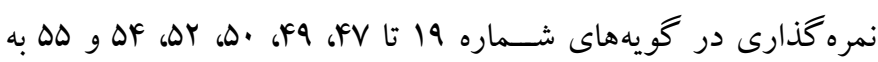
صـورت معكوس اسـت و نمره بيشـتر در اين مقياس به معناى مهارت اجتماعى بهتر است. ماتسون و اولنديكك روايى مقياس را از طريق تحليل

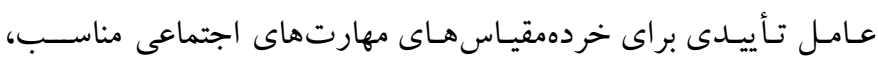

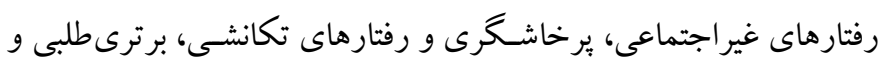

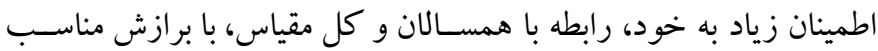

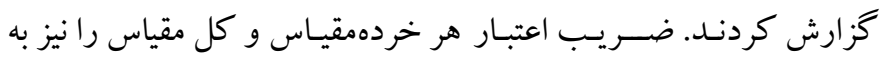

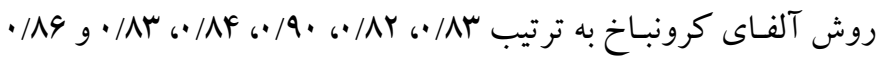

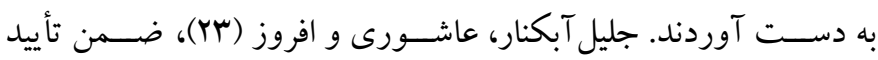

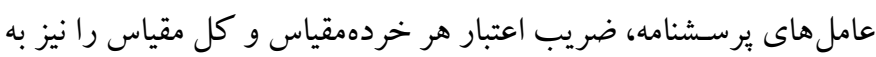

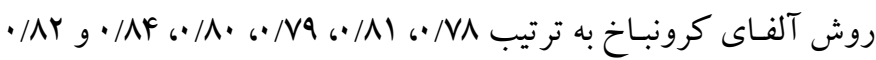

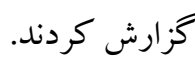
ج) برنامه مداخلهاى: برنامه فرهنگ اونى اوقات فراغت عرش بر اساس مدل

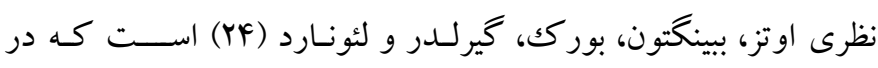

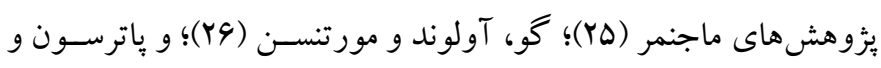

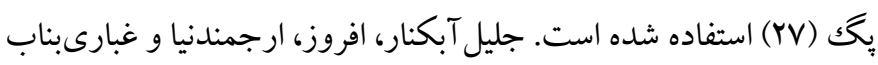

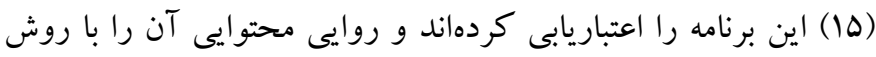

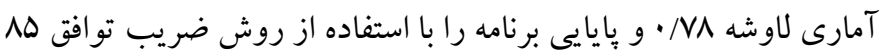

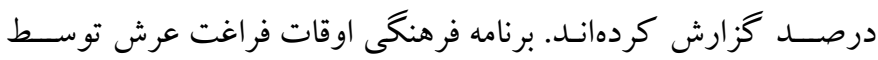

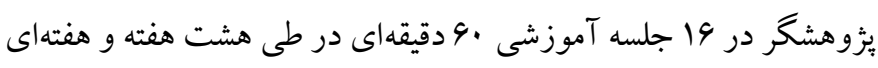

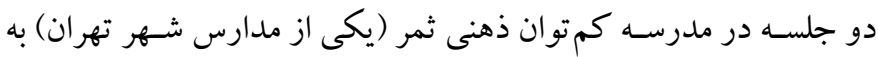
صورت گروهى آموزش داده شـد. در ضمن فاصله بين جلسات سه روز

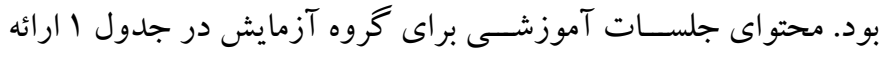

8. Lack of emotional transparency

9. Matson social skills scale

10. Appropriate social skills

11. Antisocial behaviors

12. Aggression and impulsive behaviors

13. Superiority and self-confidence

14. Relationship with peers
نفر ذكر كردند (Y). ملاككهاى ورود به يُزوهش شـامل سـن ها تا Fه سال براى مادران، ميزان تحصيلات دييلم تا كارشناسى، و وجود كم توانى ذهنى خفيف در فرزنـدان بود. معيارهاى خروج از مطالعه نيز اســفاده از ماز

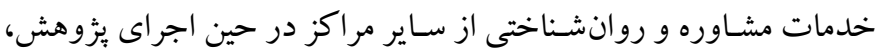

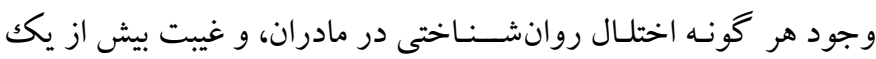
جلسه در برنامه مداخلاتى بود.

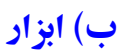
ا. مقياس دشوارىهاى تنظيم هيجانى ': اين مقياس به وسيله گُ اتز و رومر

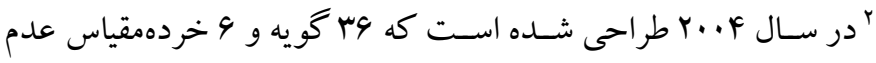

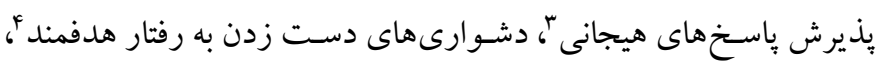

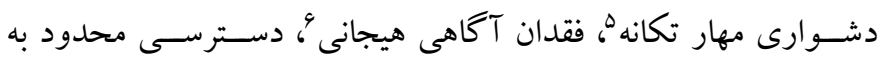

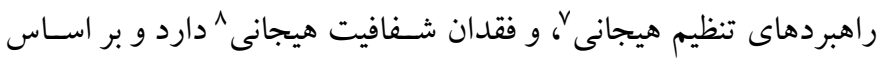

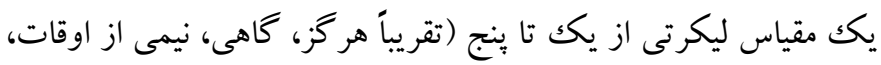

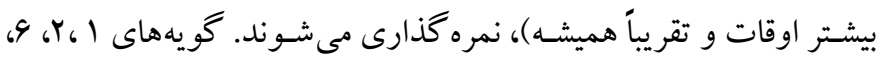

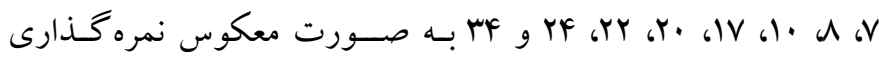

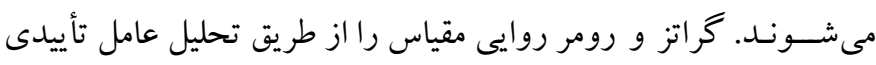

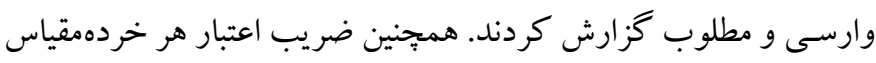

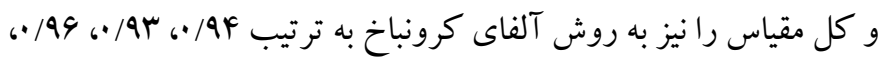

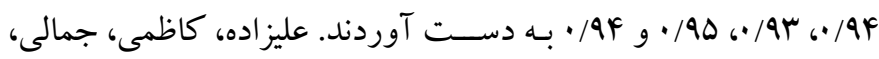

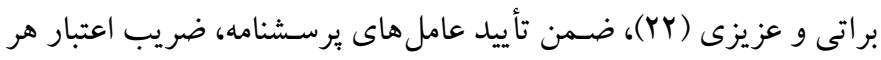

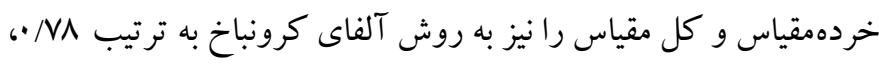
• • • • •

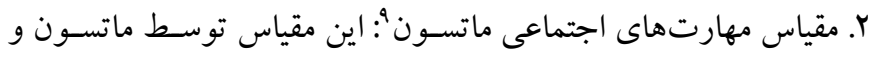

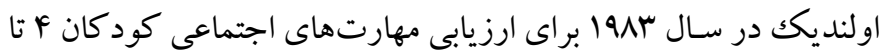

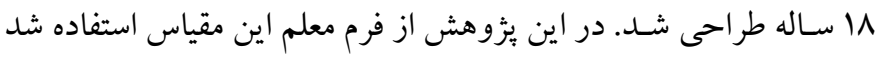

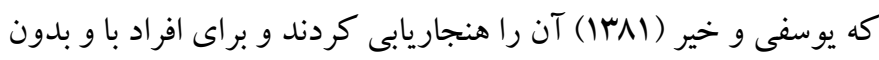

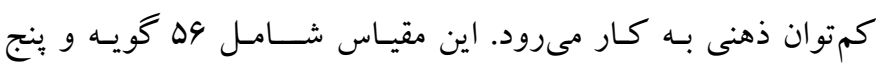

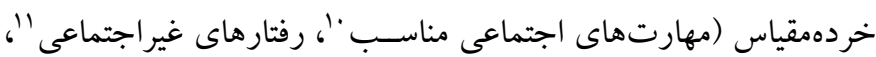

1. Difficulties of emotion regulation scale

2. Gratz \& Roemer

3. Rejection of emotional responses

4. Difficulties in engaging in purposeful behavior

5. Difficulty in controlling impulse

6. Lack of emotional awareness

7. Limited access to emotional regulation strategies 
شـــه اسـت. براى آموزش مفاهيم از روشهاى ســنرانى، توضـيحى، يرسش و ياسخ، فيلم و ياوريوينت استفاده شد.

\section{جدول ا: محتواى جلسات برنامه فرهنگى اوقات فراغت عرش}

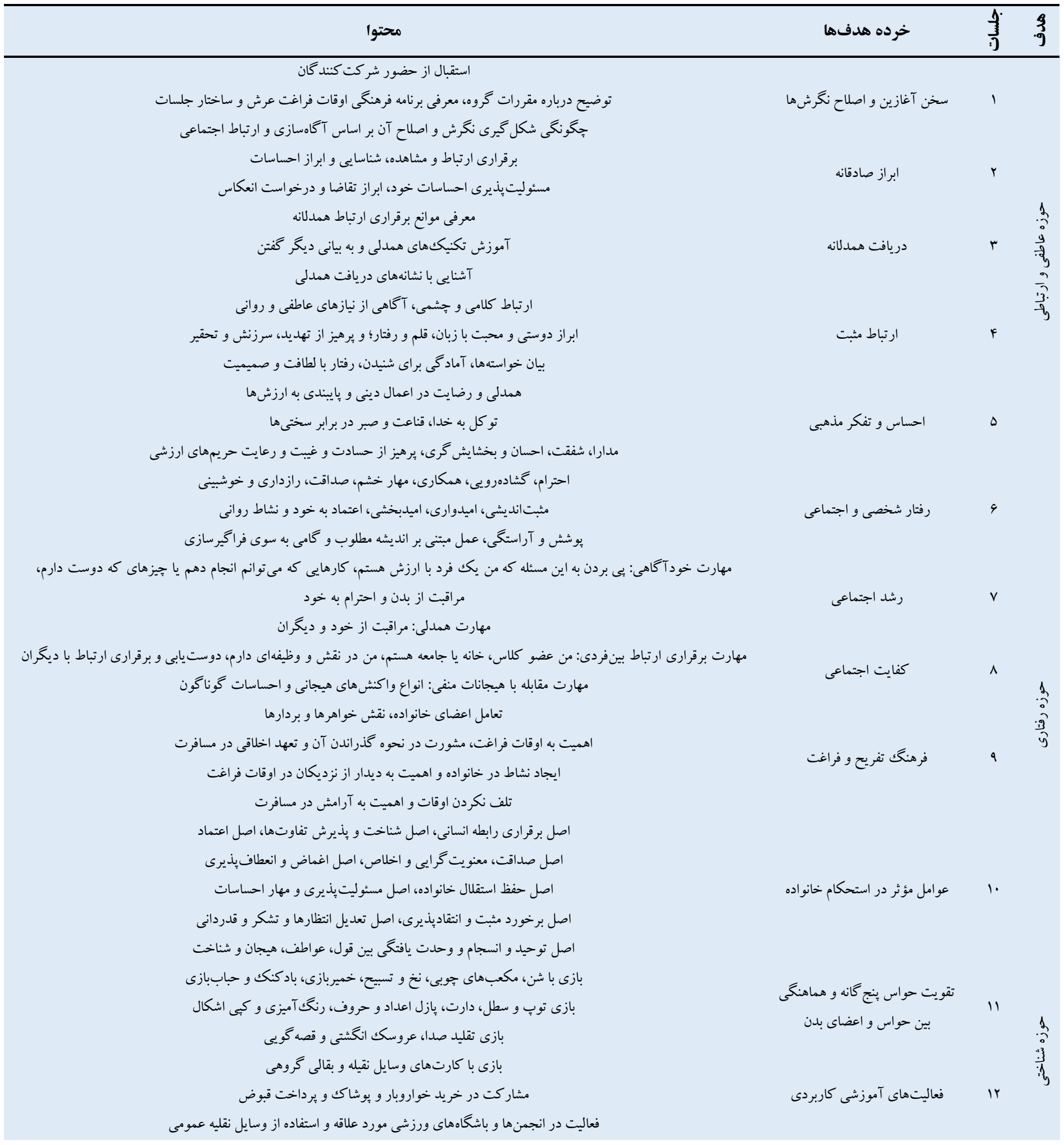


توجه شنيدارى و توجه ديدارى

حر كات موزون، حفظ توجه و تغيير آن

تقويت توجه

ir

بازى با رايانه و خواندن زيرنويس فيلمها مانها

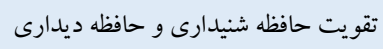

تمرين هاى حافظه شنيدارى و ديدارى

تقويت حافظه فعال

If

بازى با تصاوير، اجراى دستورها، نمايش فيلم، حافظه بازشناسى و حافظه يادآورى

تقويت توجه شنيدارى و تميز شنيدارى

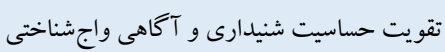

تقويت زبان

10

در كك جملهها و مسائل، درك مطلب شنيدارى، درك لغات و مفاهيم

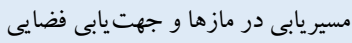

آكاهى فضايى و ادراكك شكل و زمينه

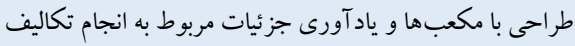

تقويت يردازش ديدارى فضايى و

سخن پيا يانى

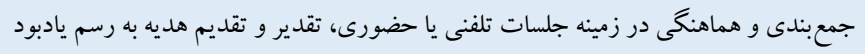

به مدت دو روز براى گروه گواه بركزار شــــ دادههاى به دسـت آمده

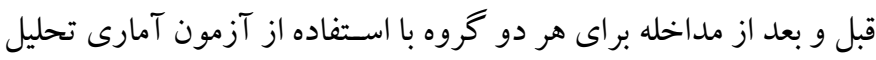
كوواريانس تككمتغيرى و جندمتغيرى تحليل شد. جهت تحليل دادهها از نسخه سץ نرمافزار آمارى SPSS استفاده شد.

\section{يافتهها}

يافته هاى توصيفى حاكى از سن آزمودنىها در گروه آزمايش با ميانخين

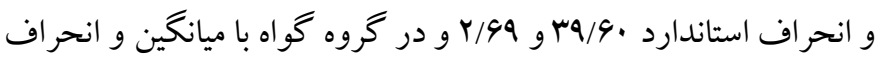

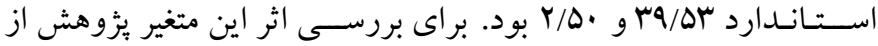

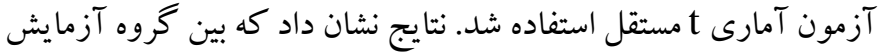

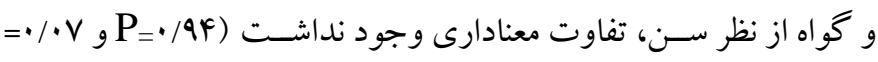
(t)

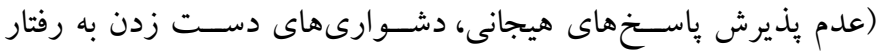
هدفمند، دشوارى مهار تكانه، فقدان آكاهى هيجانى، دسترسى محدود به

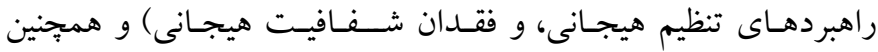

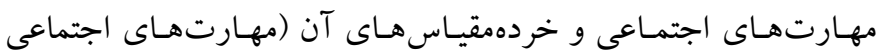

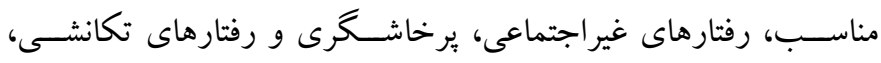

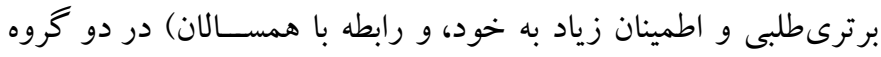

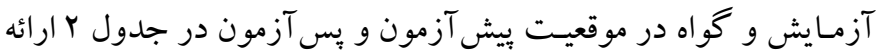

د) روش اجرا: براى انجـام يزوهش از مــديريـت آموزش و يرورش اسـتثنايى شـهر تهران، معرفى نامه دريافت شـــ و با مديريت محترم مدرسه

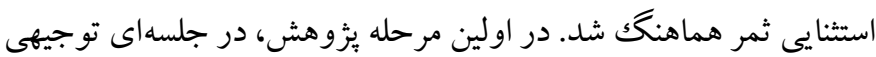
براى آزمودنى هاى انتخاب شـده، ضـمن تشـريح اهداف يزوهش از آنها

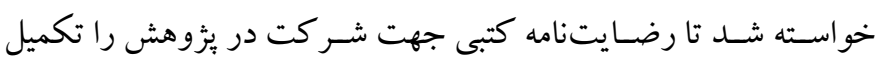

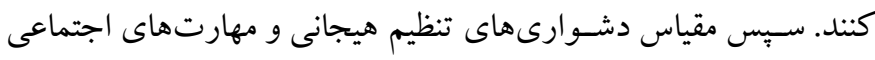

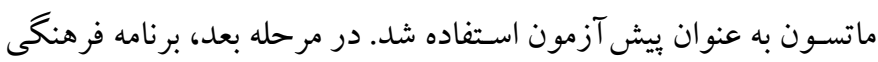
اوقات فراغت عرش براى گروه آزمايش توسط يُزوهشـر در 19 جلسـه آموزشى •و دقيقهاى در طى هشـت هفته و هفتهاى دو جلسـه اجرا شـد،

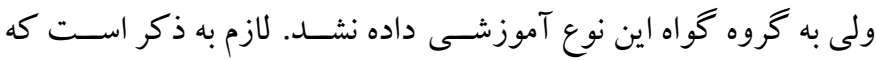
مادران به صـورت دو جلسـه در ميان و در مجموع در شـش جلســه، و فرزندان آنها در تمامى جلســات حضــور داشــتند. يس از اجراى برنامه مـداخلاتى نيز هر دو گروه با اسـتفاده از همان ابزارهاى مربوط به مرجله

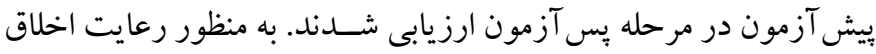

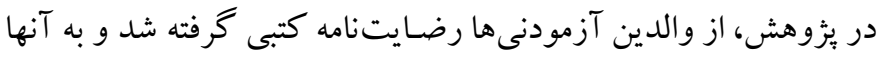

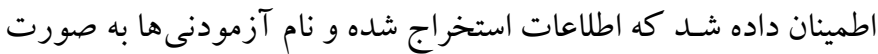
محرمانه باقى مى ماند. همجِنين به منظور حفظ اســرار شــخصسى و عدم تجاوز به حريم خصسوصى شر كت كنند كان، نتايج حاصل از يزوهش در بـ

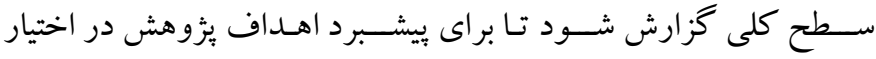
روانشـاسـان، متخصصـان و مديران مراكز دبسـتانى قرار گيرد. همجِنين

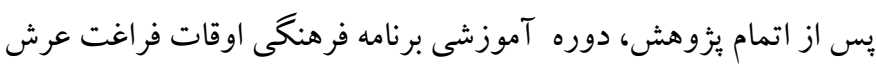


جدول r: ميانعين و انحراف معيار متغيرهاى ثزوهش در كروه آزمايش و كواه

\begin{tabular}{|c|c|c|c|c|c|c|c|c|c|}
\hline \multicolumn{4}{|c|}{ كروه كواه } & \multicolumn{4}{|c|}{ كروه آزمايش } & \multirow{2}{*}{ موقعيت } & \multirow{2}{*}{ متغيرها } \\
\hline $\mathbf{P}$ & K-S Kاره & انحر اف معيار & ميانغين & $\mathbf{P}$ & K-S Kاره & انحر اف معيار & ميانكين & & \\
\hline$\cdot / r$ &.$/ 10$ & $1 / 49$ & $r \mid / \cdot$ & $\cdot / r$ & .119 & $1 / \% 4$ & $r y / \cdot \cdot$ & ي بيش آزمون & \multirow{2}{*}{ عدم يذيرش ياسخهاى هيجانى } \\
\hline .1 .9 & $\cdot / r 1$ & $1 / \mu$ & $r \cdot / \Delta r$ &.$/ .9$ & $\cdot / r \cdot$ & $1 / \cdot 9$ & $1 N / 49$ & ֵس آزمون & \\
\hline.$/ 11$ & $\cdot / r F$ & $1 / \cdot 0$ & $\mid V / 4$. & $\cdot / 11$ & $\cdot / r$ & $\cdot / 99$ & $1 \mathrm{~V} / .9$ & 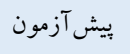 & \multirow{2}{*}{ دشوارى در رفتار هدفمند } \\
\hline$\cdot / r$ &.$/ 19$ & $1 / 11$ & IV/IT & $\cdot / r$ &.$/ 19$ & $\cdot / 91$ & $10 / 9$ & 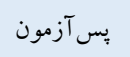 & \\
\hline.$/ 11$ & $\cdot / r$ & $1 / \cdot 1$ & $r \cdot / r$. & $\cdot / \cdot \wedge$ & $\cdot / r$. & $1 / r$ & 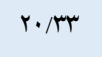 & 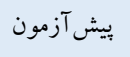 & \multirow{2}{*}{ دشوارى مهار تكانه } \\
\hline$\cdot / \cdot V$ & $\cdot / r 1$ & $1 / 1 r$ & $r \cdot / \cdot$ & $\cdot / 11$ & $\cdot /$ FF & $\cdot / \mathrm{VV}$ & $1 \Lambda / \Lambda$ & يس آزمون & \\
\hline.$/ 1 F$ &.$/ 19$ & $1 / Y F$ & 19/1r & $\cdot / r$ & $\cdot / I V$ & $1 / 1 r$ & $19 / 4$. & 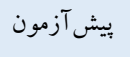 & \multirow{2}{*}{ فقدان آكاهى هيجانى } \\
\hline$\cdot / r$ & $\cdot / 19$ & $1 / 1 \Lambda$ & IN/A9 &.$/ .9$ & $\cdot / r$ & $1 / \cdot 9$ & $1 V / 49$ & بس آزمون & \\
\hline$\cdot / r$ & $\cdot / 1 \mathrm{~V}$ & $1 / r r$ & $r \mu / r$. & $\cdot / r$ & $\cdot / 10$ & $1 / \% 9$ & 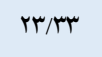 & 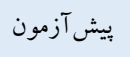 & \multirow{2}{*}{ دسترسى محدود به تنظيم هيجانى } \\
\hline$\cdot / 14$ & $\cdot / 19$ & $1 / 4$ & 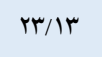 & $\cdot / \cdot \wedge$ & $\cdot / r$ & $1 / \Delta \Delta$ & $r y / \cdot$ & يس آزمون & \\
\hline.$/ 11$ & $\cdot / r \Delta$ & $\cdot / \wedge r$ & 10/1r & $\cdot 1$ & $\cdot / r$. & $1 / \cdot r$ & $\mid f / V r$ & 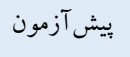 & \multirow{2}{*}{ فقدان شفافيت هيجانى } \\
\hline$\cdot / \cdot v$ & $\cdot / r$ & $\cdot / 99$ & $\mid F / \wedge 9$ & $\cdot / r$ &.$/ 19$ & $1 / F 1$ & $1 r / \cdot$ & يس آزمون & \\
\hline$\cdot / r$ & $\cdot /$ If & r & $119 / .9$ & $\cdot / r$ & $\cdot / 11$ & ५/৭9 & $110 / \wedge 9$ & 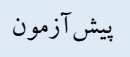 & \multirow{2}{*}{ نمره كل تنظيم هيجان } \\
\hline$\cdot / r$ & $\cdot / 10$ & $r / Y r$ & $\| F / \Delta r$ & $\cdot / r$ &.$/ T$ & $r / .9$ & $1 \cdot \Delta / r$ & 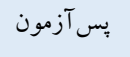 & \\
\hline$\cdot / r$ & $\cdot / 1 F$ & $1 / 4 r$ & $r \Delta / .9$ & $\cdot / r$ &.$/ A F$ & $1 / F V$ & ra/A. & 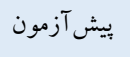 & \multirow{2}{*}{ رفتار اجتماعى مناسب } \\
\hline $.1 \cdot 9$ & $\cdot / r 1$ & $1 / \Delta r$ & $r \Delta / r^{\prime}$ & $\cdot / r$ & $\cdot / I V$ & $1 / F V$ & ra/A. & يس آزمون & \\
\hline$\cdot / r$ & $\cdot / I V$ & $1 / 1 r$ & YN/F. & .1 .9 & $\cdot / r$. & I/TF & $r / / F$ & ي بيش آزمون & \multirow{2}{*}{ رفتار غير اجتماعى } \\
\hline.$/ 1 r$ &.$/ 19$ & $\cdot / 91$ & YN/9. & $\cdot /$ & $\cdot / T r$ & $r / r v$ & $r \cdot 199$ & يس آزمون & \\
\hline .1 .9 & $\cdot / r$ & $1 / I V$ & TM/Tr & $\cdot / r$ & $\cdot / I V$ & $1 / \mu_{\Lambda}$ & $\mathrm{rN} / \cdot 9$ & 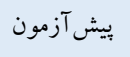 & \multirow{2}{*}{ يرخاشگرى و رفتار تكانشى } \\
\hline .1 .4 & $\cdot / r \mid$ & $1 / Y F$ & YN/FG &.$/ .9$ & $\cdot / r$. & $1 / 94$ & rQ/Vr & يس آزمون & \\
\hline $.1 \cdot 9$ & $\cdot / r$ & $1 / Y F$ & $\Lambda / f$. & $\cdot / 11$ & $\cdot / r$. & $1 / \cdot 1$ & $\Lambda / r$. & ميّش آزمون & \multirow{2}{*}{ برترىطلبى و اطمينان به خود } \\
\hline .1 .9 & $\cdot / r$ & $1 / Y F$ & N/9. & $\cdot / \Lambda$ & $\cdot / \Lambda$ & $1 / \Delta F$ & $9 / 9$. & يس آزمون & \\
\hline .1 .9 & $\cdot / r$ & $1 / Y F$ & $10 / 4$ & $\cdot / I V$ & $\cdot / \Lambda$ & $1 / 1 \wedge$ & $10 / \Delta r$ & ي بيش آزمون & \multirow{2}{*}{ ارتباط با همسالان } \\
\hline$\cdot / r$ & $\cdot / I V$ & $1 / K F$ & $10 / 99$ & $\cdot / r$ &.$/ 19$ & $1 / \Delta r$ & $19 / 1$. & "ِس آزمون & \\
\hline$\cdot / r$ & .1 & $r / V Y$ & $110 / 9$ & $\cdot / r$ & .119 & $r / F r$ & $110 / Y 9$ & ي بيش آزمون & \multirow{2}{*}{ نمره كل مهارتهاى اجتماعى } \\
\hline$\cdot / r$ & $\cdot / 10$ & $r / V F$ & $119 / 9$. & $\cdot / r$ & $\cdot / I V$ & $r / 99$ & $|r| / \pi r$ & يس آزمون & \\
\hline
\end{tabular}

تنـظيـم هيـجـان و مههارتهـاى اجتمـاعى و همجنين براى تحليـل

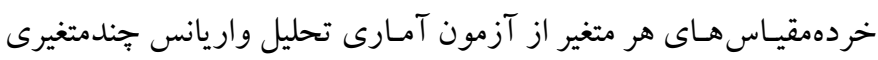

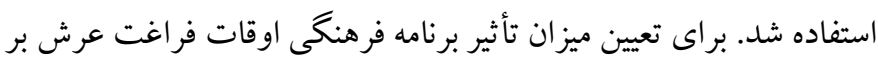

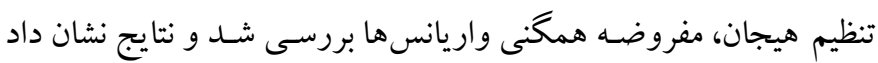

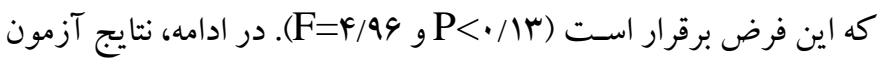

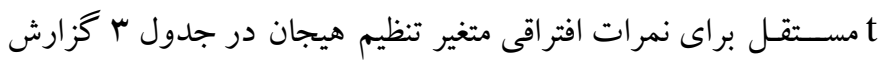
شده است.
ميـانگين و انحراف اســــانـدارد نمرات بيش آزمون و پِّ آزمون

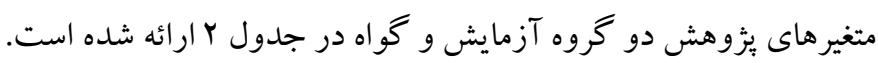
بر اساس اين جدول، مفروضه نرمال بودن توزيع دادهها در همه متغيرها با بال

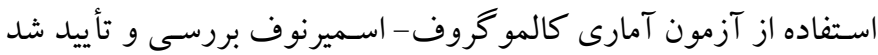

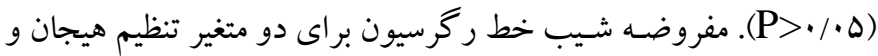
مهارتهاى اجتماعى و همجنين خردممقياس هاى آنها بر رسى شد و نتايج

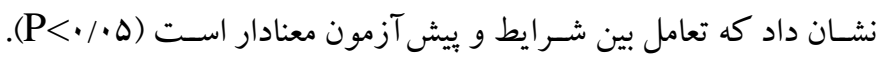

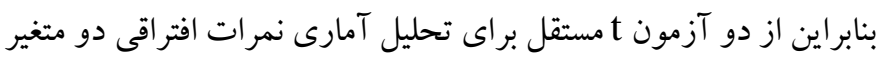


جدول "ז: نتايج آزمون t مستقل براى نمر ات افتراقى تنظيم هيجان

\begin{tabular}{|c|c|c|c|c|c|c|}
\hline اندازه اثر & نتيجه آزمون & تفاوت ميانكين & انحراف معيار & ميانكين & تعداد & كروه \\
\hline \multirow{2}{*}{$r / .+A$} & $\left(t_{(Y \Lambda)}=I 1 / r r\right.$ & $9 / 14$ & $r / 91$ & 1.199 & 10 & آزمايش \\
\hline & $<\cdot / \cdots$, & & $1 / 1 \Lambda$ & 1/or & 10 & كو اه \\
\hline
\end{tabular}

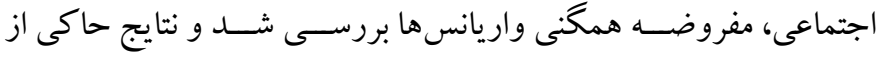

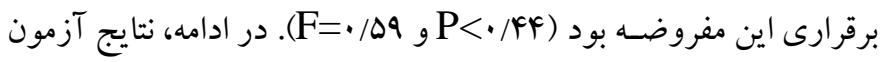

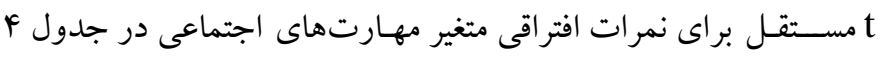
كزارش شده است.
بـا توجـه بـه نتـايج جـدول سا، برنامه فرهنكَى اوقات فراغت عرش اثر

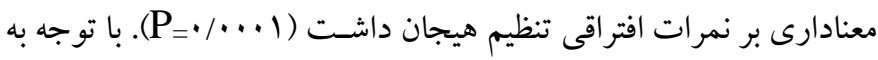

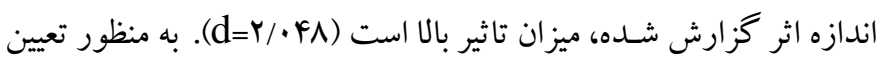

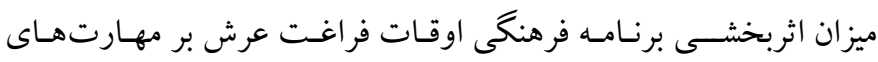

جدول ع: نتايج آزمون t مستقل براى نمرات افتراقى مهارتهاى اجتماعى

\begin{tabular}{|c|c|c|c|c|c|c|}
\hline اندازه اثر & نتيجه آزمون & تفاوت ميانكين & انحر اف معيار & ميانكين & تعداد & كروه \\
\hline \multirow{2}{*}{$1 / 190$} & $\left(\mathrm{t}_{(Y \Lambda)}=1 \cdot / Y Y\right.$ & $F / a r$ & $1 / \Delta r$ & $\Delta / ৭ r$ & 10 & آزمايش \\
\hline & $<\cdot / \cdots \cdot \mid$ & & $1 / .9$ & $1 / \cdot$ & 10 & كواه \\
\hline
\end{tabular}

افتراقى خردهمقياس هاى تنظيم هيجان (متغير هاى عدم يذيرش باســخهاى

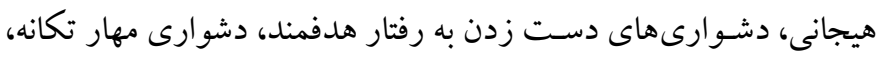

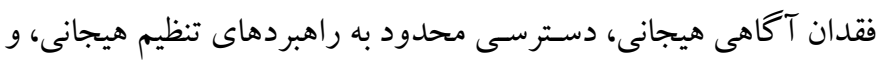

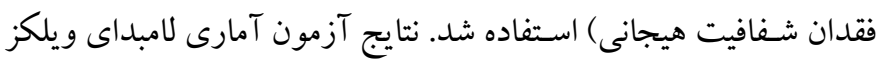
نشان داد كه خردهمقياسهاى تنظيم هيجان در گروههاى آزمايش و گتواه

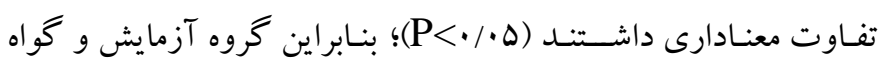

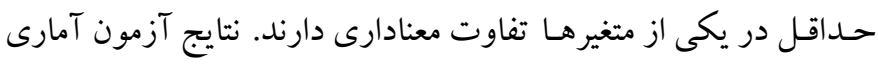

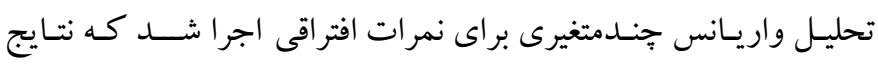
تفكيكى آن در جدول ه گزارش شده است.
نتايج جدول F نشــان داد كه برنامه فرهنگ اوقات فراغت عرش اثر

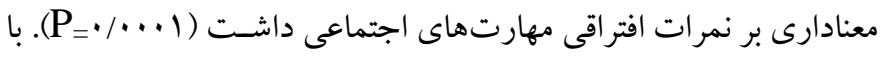

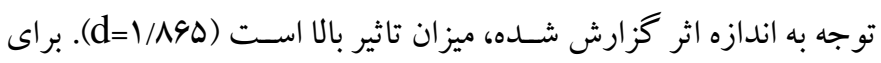

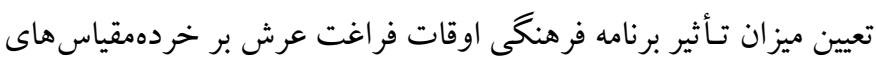

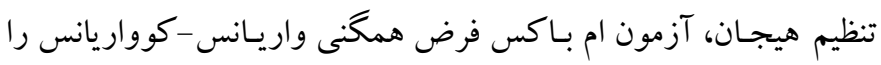

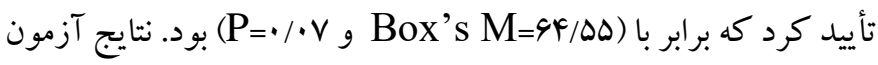

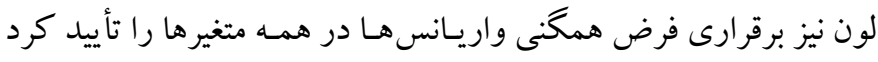

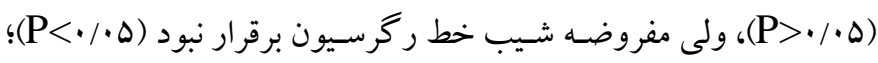

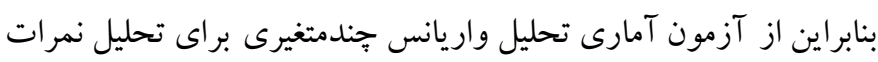

جدول 0: نتايج تفكيكى تحليل واريانس جندمتغيرى براى خردهمقياسهاى تنظيم هيجان

\begin{tabular}{|c|c|c|c|c|c|c|c|}
\hline توان آزمون & مجذور اتا & سطح معنادارى & Tاره F F & ميانگين مجذورات & درجه آزادى & مجموع مجذورات & متغير هاى وابسته \\
\hline $1 / \cdot \cdot$ & $\cdot / 4 \Lambda$ & $\cdot \cdots \cdot 1$ & $4 N / 9$ & $r \cdot / \cdot \cdot$ & 1 & $r \cdot / \cdot \cdot$ & عدم يذيرش ياسخهاى هيجانى \\
\hline.$/ 99$ & . Ar & $\cdot / \cdots 1$ & $r \cdot / 91$ & $1 \cdot / \wedge$ & 1 & $1 \cdot / \wedge$ & دشوارى در رفتار هدفمند \\
\hline.$/ 99$ & . $/ 4 r$ & $\cdot / \cdots 1$ & $r \cdot / \Delta \Lambda$ & $\mid F / v$. & 1 & $\mid F / v$. & دشوارى مهار تكانه \\
\hline $1 / \cdot$ & $\cdot / \Delta r$ & $\cdot / \cdots 1$ & $\mathrm{rI/lI}$ & $r F / r$. & 1 & $r F / r$. & فقدان آكاهى هيجانى \\
\hline $1 / \cdot \cdot$ & $\cdot / \mathrm{v}$ & $\cdot / \cdots \cdot$ & $99 / \pi r$ & rN/Dr & 1 & rN/Dr & دسترسى محدود به تنظيم هيجانى \\
\hline.$/ 99$ & $\cdot / A r$ &.$\cdots 1$ & $r \cdot 190$ & $19 / 14$ & 1 & $19 / 14$ & فقدان شفافيت هيجانى \\
\hline
\end{tabular}

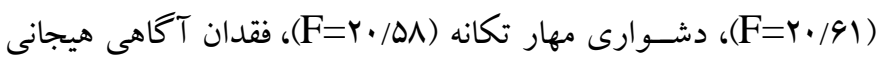

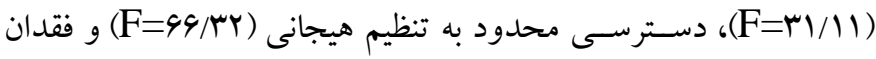

بـا توجه به نتايج جدول ه، گروه اثر معنادارى بر نمرات افتراقى عدم

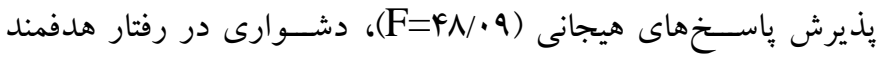




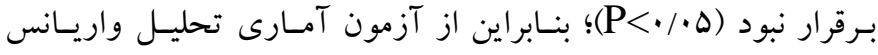

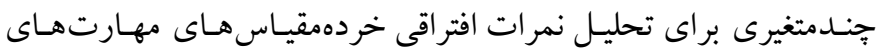

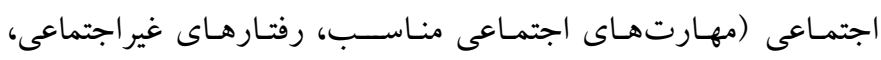

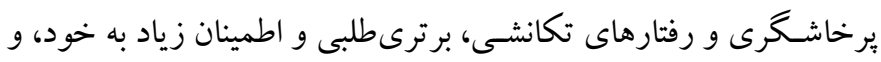

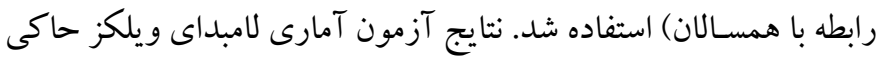

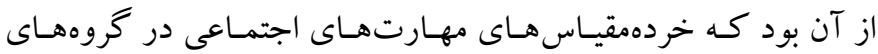

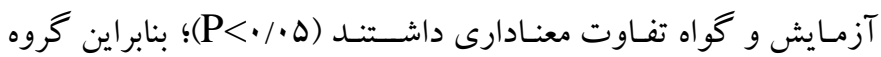

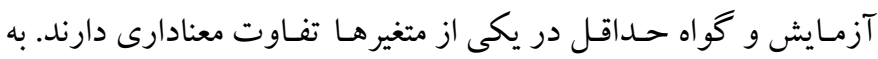

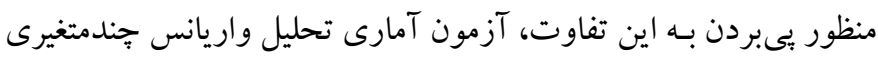

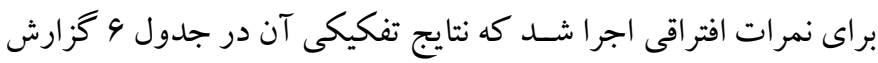
شده است.

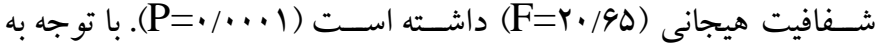

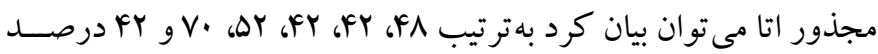

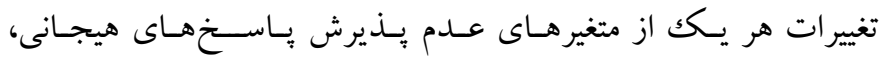
دشـوارى هاى دسـت زدن به رفتار هدفمند، دشـوارى مهار تكانه، فقدان

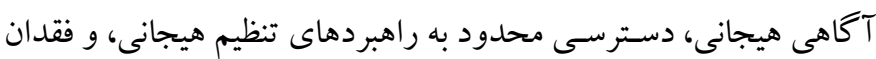

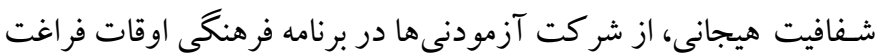
عرش ناشى مى شود.

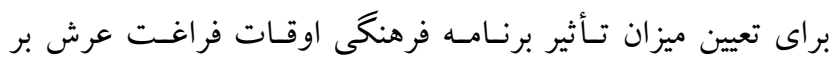

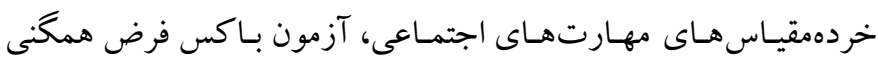

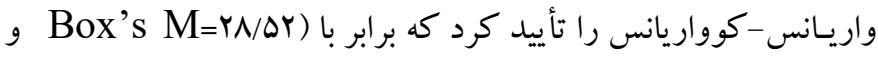

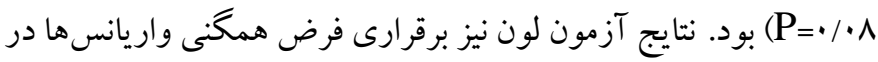

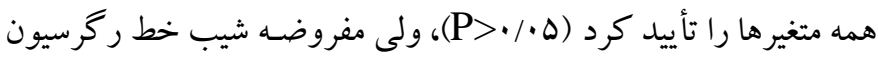

واستول 7: نتايج تفكيكى تحليل واريانس جندمتغيرى براى نمرات افتراقى خردهمقياسهاى مهارتهاى اجتماعى

\begin{tabular}{|c|c|c|c|c|c|c|c|}
\hline توان آزمون & مجذور اتا & سطح معنادارى & T آماره F & ميانكين مجذورات & درجه آزادى & مجموع مجذورات & متغير هاى وابسته \\
\hline $1 / \cdot \cdot$ & $\cdot / \mathrm{V}$ & $\cdot \cdots \cdot 1$ & SV/rT & IV/9Y & 1 & IV/9T & مهارتهاى اجتماعى مناسب \\
\hline$\cdot / 99$ & $\cdot / 4 \pi$ & $\cdot / \cdots \cdot 1$ & $r M / I V$ & $F / \cdot r$ & 1 & $F / \cdot r$ & رفتارهاى غير اجتماعى \\
\hline $1 / \cdot$ & $\cdot / N 1$ &.$/ \cdots 1$ & $9 V / F F$ & IV/9r & 1 & IV/ar & يرخاشكرى و رفتارهاى تكانشى \\
\hline $1 / \cdot \cdot$ & $\cdot / \Delta \mathrm{V}$ & $\cdot / \cdots 1$ & rV/A. & $1 \cdot / \wedge$. & 1 & $1 \cdot / \wedge$. & برترى طلبى و اطمينان زياد به خود \\
\hline $1 / \cdot$ & $\cdot 109$ & $\cdot \cdots 1$ & $r \Delta / v q$ & $\mathrm{~V} / \Delta$. & 1 & $\mathrm{~V} / \Delta$. & رابطه با همسالان \\
\hline
\end{tabular}

ذهنى انجام شــــ. يافته ها نشــان داد كه آموزش برنامه اوقات فراغت بر تنظيم هيجان مادران و مهارت هاى اجتماعى كود كان كم توان ذهنى در آزمودنى هـا، اثر مثبـت و معنـادارى داشــت. اين يـافتـه بـا نتايج بئوهش جليـل آبكنـار، افروز، ارجمنـدنيـا و غبارىبناب (If) مبنى بر اثربخشـى إ) آموزش برنـامـه فر هنكى اوقـات فراغـت عرش بر ظرفيـت شـــــاختى و مهارت هاى ارتباطى دانش آموزان كم تو ان ذهنى؛ يافته هاى بثوهش كم، خندقى و مشــهدى (19) درباره تأثير برنامههاى درسسى اوقات فراغت بر كاهش مشـكلات رفتارى دانش آموزان؛ و همجنين نتايج مطالعه زارع و مـالكى عـذارى (IV) مبنى بر تـأثير گحذران اوقـات فراغت بر كاهش مشـكلات رفتارى دانش آموزان همخوانى داشــت. علاوه بر اين، نتايج يثزوهش حاضـر با يافتهاى بثزوهش هاى هوشينا، جيانويلو و سو كايا (1) مبنى بر تـأثير قـابـل توجه بازىدرمانى ديجيتالى به عنوان نوعى برنامه فراغتى بر كاهش مشكلات رفتارى كود كان؛ نتايج يزوهش بوسينك، ون
بـا توجـه بـه نتـايج جــدول 9، گروه اثر معنـادارى بر نمرات افتراقى

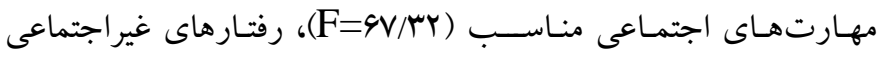
(F=rI/IV) و اطمينان زياد به خود ( • F=rV/A)، و رابطه با همسـالان (F=rه/Vq)

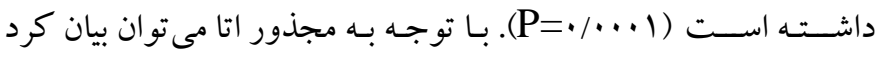

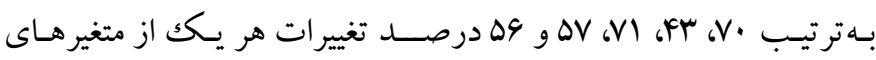
مهارت هاى اجتماعى مناســب، رفتارهاى غيراجتماعى، برخاشــرى و رفتارهاى تكانشى، برترىطلبى و اطمينان زياد به خود، و رابطه با همسالان از شـــركت آزمودنى هـا در برنـامه فرهنكى اوقات فراغت عرش ناشـى مى شود. بحث و نتيجه Fيرى يثزوهش حاضسر با هدف بررسى اثربخشى برنامه فرهنكى اوقات فراغت عرش بر تنظيم هيجان مادران و مهارتهاى اجتماعى كود كان كمتوان 
كنـد تـا مهارت هـاى اجتماعى آنها بهبود ييدا كند. مشــار كت مثبت در فعاليتهاى اوقات فراغت موجب تقويت اعتماد به خود، نشــاط روانى و

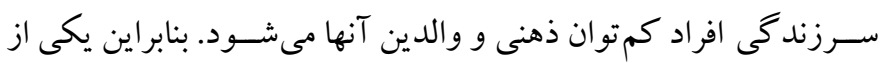

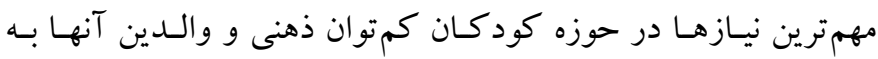

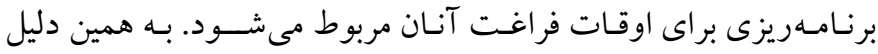

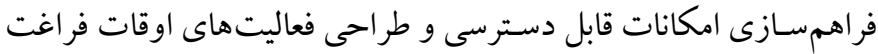

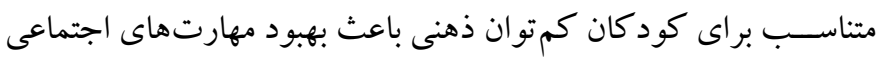

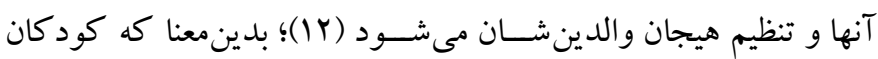

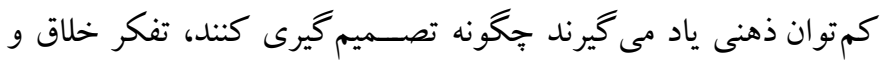

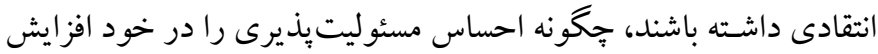

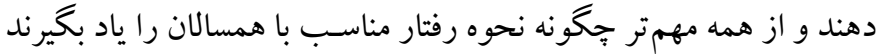

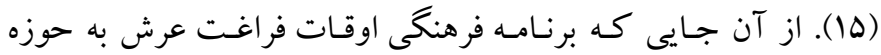

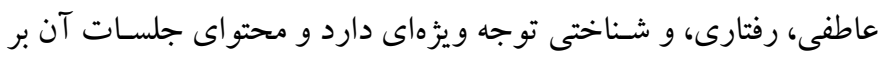
همين اسـاس تدوين شـده اسـت دور از انتظار نيسـت كه اجراى خجنين برنـامهاى ســبـب تنظيم هيجـان مـادران و بهبود مهارتهاى اجتماعى

$$
\text { دانش آموزان كم توان ذهنى شود. }
$$

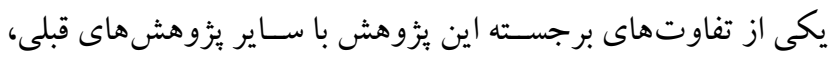

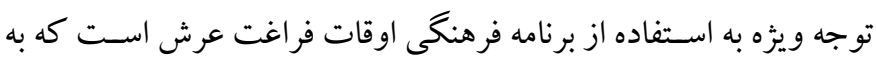

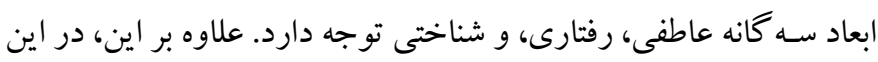

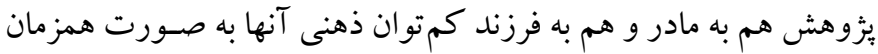

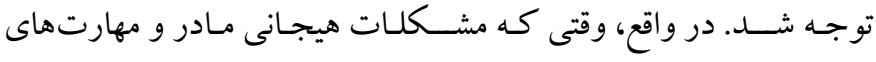

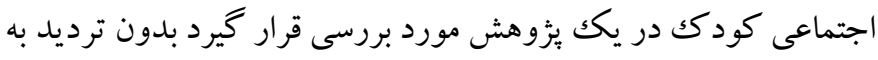

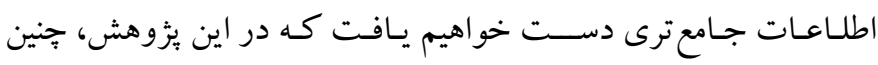
شـــايطى فراهم شــد. علـاوه بر اين، تنظيم هيجـان در مـادران و بهبود مهارتهاى اجتماعى در كودكان موجب ارتباط مؤثر والدين با فرزندان شـد و بدون ترديد، نقش مهمى در بذيرش اجتماعى آنها خو اهد داشـت.

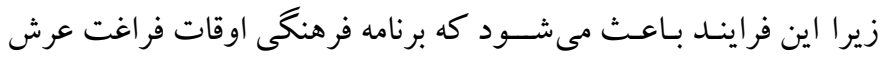

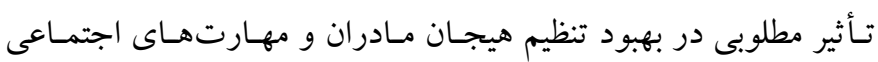
فرزندان كمتوان ذهنى آنها ايجاد كند.

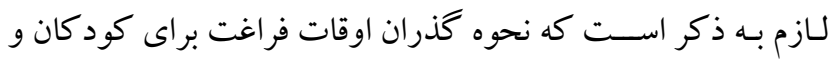
نوجو انان با نيازهاى ويزه بهطور عام و براى كود كان كم توان ذهنى به بطور

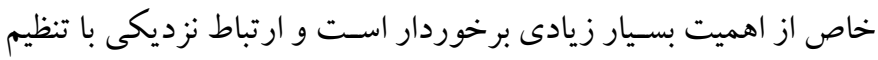

در بوتن و ولاسـكامٍ (11) مبنى بر سـطح بايين فعاليتهاى جسـمى و

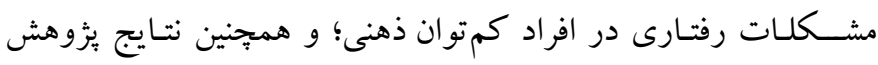

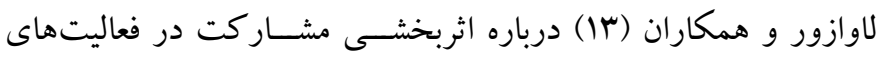
فراغتى بر سـلامت روانى آزمودنىها همسـو بود. در ضـمن نتايج اين

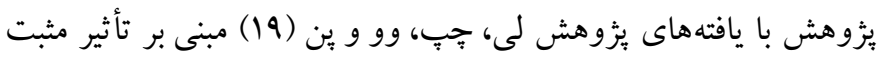
و قابل توجه مشــاركت در فعاليتهاى فراغتى بر مشـكلات رفت رفتارى نوجو انان با نشانگًان داون، همخوانى داشت.

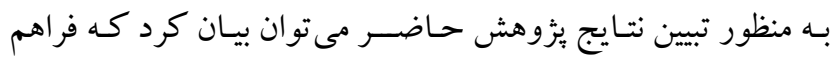

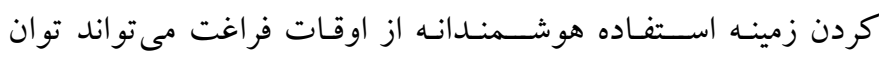

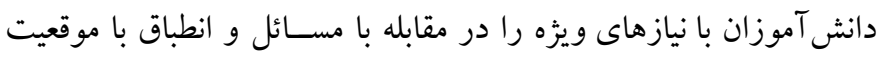

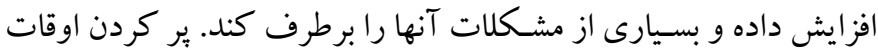

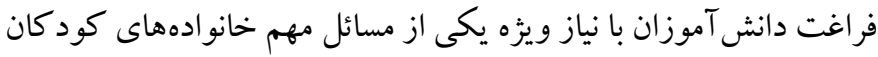

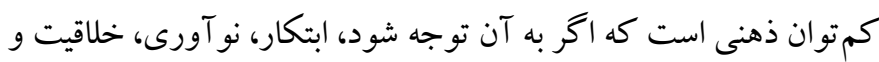

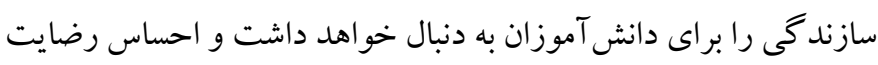

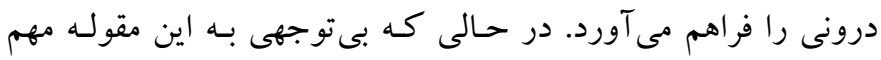

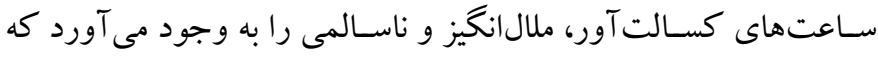

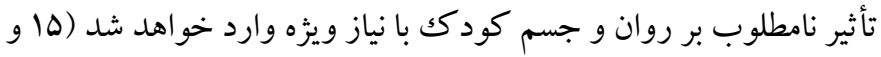

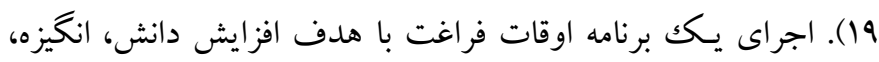

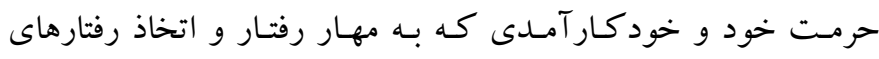

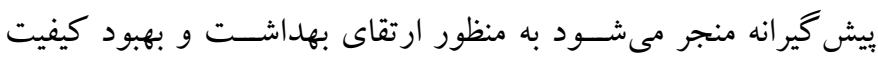

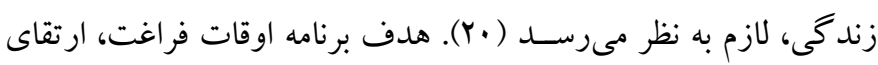

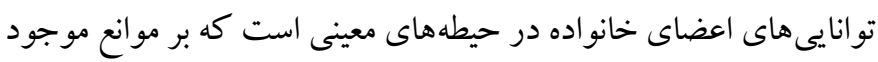
در زمينه هاى مهار هيجانها و مهارتهاى اجتماعى كود كان موفق شوند.

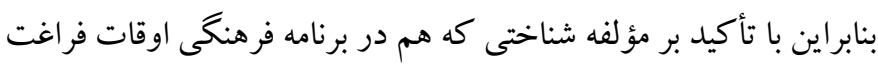

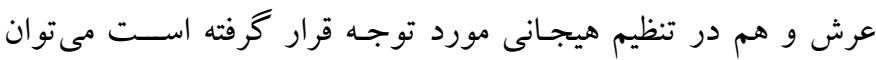

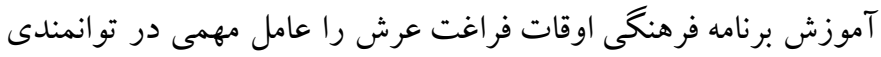

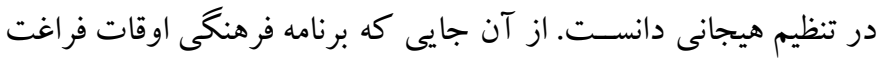

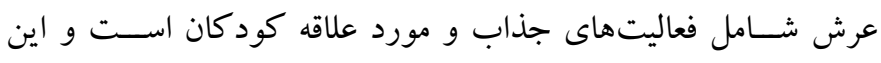

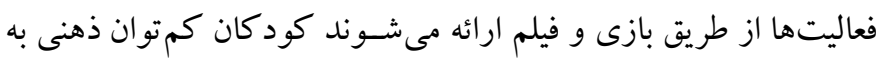

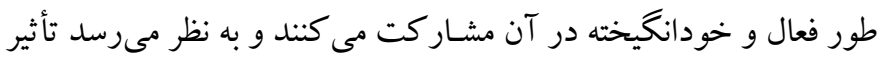
قابل توجهى بر بهبود مهارتهاى اجتماعى آنها دارد. برنامه اوقات فراغت

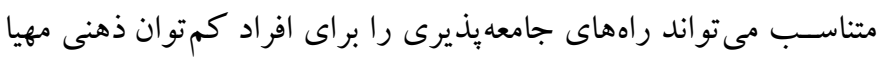


و اين برنامه آموزشسى در مدارس به صسورت رايكان اجرا شـود تاميزان اثربخشى آن بر كروههاى مختلف، وارسى و مقايسه شود.

\section{ملاحظات اخلاقى}

بيروى از اصـول اخلاق ثئوهش: مجوز اجراى اين مطالعه بر روى افراد نمونه از از

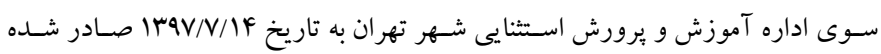

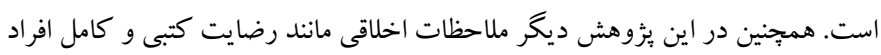

نمونه و رعايت اصل رازدارى و محرمانه ماندن اطلاعات، رعايت شده است. حامى مالى: اين مطالعه بدون حامى مالى و در قالب پايانانامه كارشـاسى ارشد انجام

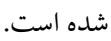

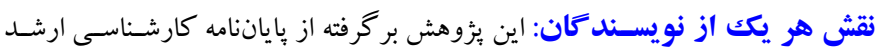

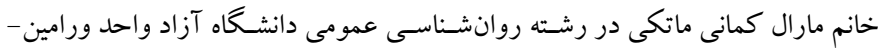

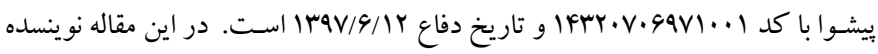

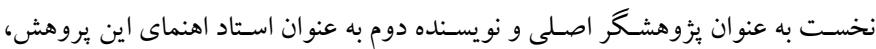
نقش داشتند. تضـاد منافع: انجام اين يُووهش براى نويسـند كان هيج گُونه تعارض منافع را به دنبال

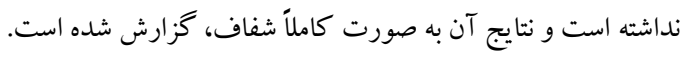
تشـكر و قدر دانى: بدين وسـايل از مسئولان اداره آموزش و يرورش شـهـهر تهران

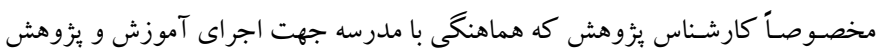

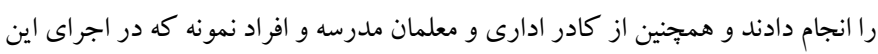
طرح به ما كمك كردند، تشكر و قدردانى مى دود داند.
هيجان و مهارتهاى اجتماعى آنها دارد. در واقع، برنامه فرهنكى اوقات

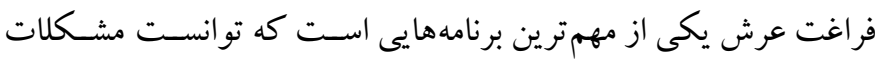

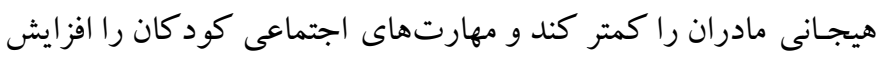
دهد.

در بزووهش حاضـر از برنامه مداخلاتى خاصى براى كود كان كم توان

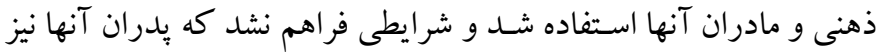

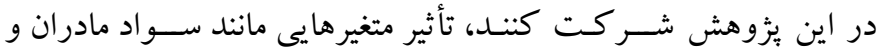

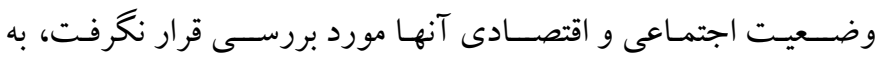

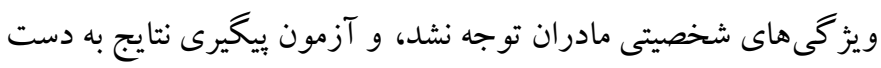

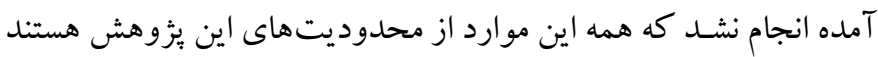
و بايد در تعميم نتايج با احتياط عمل كرد. در همين راستا ييشنهاد مى شود

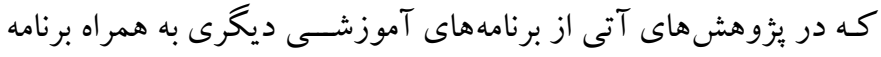

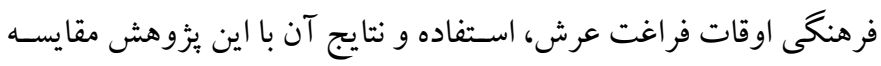

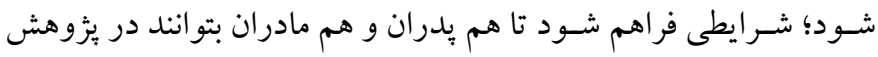
شـركت كنند؛ سـواد والدين و وضسعيت اجتماعى و اقتصـادى آنها مورد

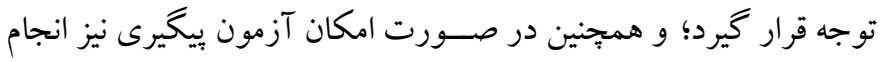

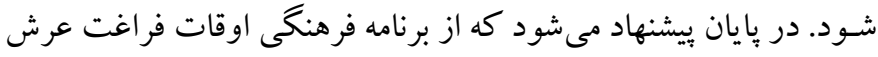

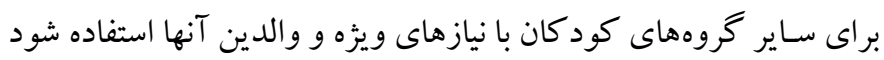




\section{References}

1. Ashori M, Norouzi Gh, Jalil-Abkenar SS. The effect of positive parenting program on mental health in mothers of children with intellectual disability. JOID. 2019; 23(3): 385-396. Doi: 10.1177/17446295188 24899 [Link]

2. Ashori M, Nakhostin N, Ghazaghi T. The effect of mental immunization training on psychological reactions and social competency of students with intellectual disability. J Child Ment Health . J Child Ment Health. 2019; 5(4): 13-26. [Persian]. [Link]

3. Yoosefi lebni J, Ziapour A, Khosravi B, Rahimi khalifeh kandi Z. Lived experience of mothers of children with disabilities: a qualitative study of Iran. J Public Health. 2020; 1-7. Doi:10.1007/s10389-02001215-0 [Link]

4. Gregoire S, Lachance L. Taylor G. Mindfulness, mental health and emotion regulation among workers. I J W. 2015; 5(4), 96-119. Doi.org/10.5502/ijw. v5i4.444 [Link]

5. Quoidbach J, Berry EV, Hansenne M, Mikolajczak M. Positive emotion regulation and well-being: Comparing the impact of eight savoring and dampening strategies. Personality and Individual Differences. 2010; 49(5): 368-373. Doi:10.1016/j .pa id.2010.03.048 [Link]

6. Ashori M. The effectiveness of life skills training on the social skills of deaf students. Biomed J Sci \& Tech Res, 2019; 19(3): 14276-14280. Doi: 10.26717/ BJS TR.2019.19.003291[Link]

7. Jalil-Abkenar S, Afrooz G, Arjmandnia A, GhobariBonab B. The effictiveness of Arsh Leisure Time Program on the working memory, cognitive capacity and communication skills of children with intellectual disability. Psychology of Exceptional Individuals, 2018; 8(30): 47-72. [Persian]. Doi: 10.22054/jpe. 2018.9207 [Link]

8. Bigby C, Craig D. A case study of an intentional friendship between a volunteer and adult with severe intellectual disability: "My life is a lot richer!" J Intellect Dev Disabil. 2017; 42(2): 180-189. Doi. org/10.14201/scero2017484766 [Link]

9. Beh-pajooh A. Principles of communication with children and adolescents ( $9^{\text {th }}$ Ed). Tehran: Danzheh Puplication. 2013. [Persian]. [Link]

10. Matsunaga T, Naito M, Wakai K, Shigekazu Ukawa SH, Zhao W, Okabayashi S, Ando M, Kawamura T, Tamakoshi A. Leisure-time physical activity and risk of disability incidence: A 12-year prospective cohort study among young elderly of the same age at baseline. J Epidemiol. 2017; 27: 538-545. Doi: 10. 1016/j.je.2016.11.004 [Link]

11. Bossink LWM, Van der Putten AAJ, Vlaskamp C. Understanding low levels of physical activity in people with intellectual disabilities: A systematic review to identify barriers and Facilitators. Res Dev Disabil. 2017; 68; 95-110. Doi: 10.1016/j.ridd. 2017 . 06.00 [Link]

12. Chien CW, Rodger S, Copley J. Differences in patterns of physical participation in recreational activities between children with and without intellectual and developmental disability. Res Dev Disabil. 2017; 67: 9-18. Doi: 10.1016/j.ridd .2017. 05. 007 [Link]

13. Levasseura M, Lefebvrec H, Levertc MJ, Bédarda JL, Desrosiersd J, Therriaulte PY, Tourigny A, Couturierd Y. Carbonneaue H. Personalized citizen assistance for social participation (APIC): A promising intervention for increasing mobility, accomplishment of social activities and frequency of leisure activities in older adults having disabilities. Arch Gerontol Geriatr. 2017; 64: 96-102. Doi: 10.1016/j.archger.2016.01.001 [Link]

14. Eratay E. Effectiveness of leisure time activities program on social skills and behavioral problems in individuals with intellectual disabilities. Educ. Res. Rev. 2013; 8(16): 14-37. Doi: 10.5897/ERR2013. 1509 [Link]

15. Jalil-Abkenar S, Afrooz G, Arjmandnia A, GhobariBonab B. Designing and validation Arsh Leisure Time Program for improvement of working memory, cognitive capacity and communication skills of slow paced students. Empowering Exceptional Children, 2018; 9(1): 7-20. [Persian]. Doi: 10.22034/ceciranj. 2018.68952 [Link]

16. Kam A, Amin Khandaghi M, Mashhadi A. The impact of leisure curriculum on leisure skills of the male secondary school students in Mashhad. Research in Curriculum Planning. 2015; 12(2): 128-141. [Persian]. [Link]

17. Zare B, Maleki A. The study of relation between value system and youths' way of spending leisure time in Dasht-e Azadegan. Quarterly Journal of Iranian Association for Cultural Studies \& Communication. 2015; 11(39): 143-172. [Persian]. [Link]

18. Hoshina AHR, Giannopulu I, Sugaya M. Measurement of the effect of digital play therapy using biological information. Procedia Computer Science. 2017; 112: 1570-1579. Doi.org/10.1016/ j. procs.2017.08.104 [Link] 
19. Lee HY, Yu ChP, Wu ChD, Pan WCh. (2018). The effect of leisure activity diversity and exercise time on the prevention of depression in the middle-aged and elderly residents of Taiwan. Int J Environ Res Public Health. 2018; 15: 654. Doi: 10.3390/ijerph15040654 [Link]

20. Wiskochil B, Lieberman L, Houston W, Petersen S. The effects of trained peer tutors on the physical education of children who are visually impaired. JVIB. 2007; 101(6): 339-350. Doi.org/10.1177/ 0145 482X0710100604 [Link]

21. Gall M, Borg W, Gall J. Quantitative and qualitative methods of research in psychology and educational science. Nasr A, Arizi H, Abolghasemi M, Pakseresht MJ, Kiamanesh A, Bagheri Kh, et al. (Persian translator) 1th edition. Tehran: Samt. 2003; pp: 189190. [Persian]. [Link]

22. Alizade A, Kazemi D, Jamali Z, Barati M, Azizi M. The role of emotional regulation and sspirituality on ooccupational stress in mental health of deaf people. Military Nurses. 2014; 2(2): 17-22. [Persian]. [Link]

23. Jalil-Abkenar SS, Ashori M, Afrouz GA. The eeffect of social behaviors training on improvement of the social skills of aadolescents with intellectual disability. Archives of Rehabilitation. 2013; 14(3): 3140. [Persian]. [Link]

24. Oates A, Bebbington A, Bourke J, Girdler S, Leonard H. Leisure participation for school-aged children with Down syndrome. Disability and Rehabilitation. 2011; 33: 1880-1889. Doi: 10.3109/09638288.2011.553701 [Link]

25. Majnemer A. Promoting participation in leisure activities: Expanding role for pediatric therapists. Phys Occup Ther Pediatr. 2009; 29(1): 1-5. Doi: 10. 1080/01942630802625163 [Link]

26. Gow AJ, Avlund K, Mortensen EL. Leisure activity associated with cognitive ability level, but not cognitive change. Front Psycholo. 2014; 5: 68-79. Doi: 10.3389/fpsyg.2014.01176 [Link]

27. Patterson I, Pegg S. Serious leisure and people with intellectual disabilities: benefits and opportunities. Leisure Studies. 2009; 28(4): 387-402. Doi: 10. 1080/ 02614360903071688 [Link] 